\title{
1 Seismic Hazard and Risk in Bhutan
}

2 Victoria L. Stevens ${ }^{1}$, (ORCID: 0000-0003-3174-9949)

3 Raffaele De Risi², (ORCID: 0000-0002-5496-9656)

4 Romain Le Roux-Mallouf ${ }^{3}$, (ORCID: 0000-0002-6869-3910)

5 Dowchu Drukpa ${ }^{4}$, (ORCID: 0000-0001-6642-2829)

6 György Hetényi ${ }^{5}$, (ORCID: 0000-0001-9036-4761).

7

1. University of Cape Town, Geological Sciences Department, Cape Town, South Africa

2. University of Bristol, School of Civil, Aerospace and Mechanical Engineering, Bristol, UK

3. Geolithe, Research and Development, Crolles, France

4. Department of Geology and Mines, Earthquake and Geophysics Division, Thimphu, Bhutan

5. University of Lausanne, Institute of Earth Sciences, Lausanne, Switzerland

Corresponding Author: Victoria Stevens (ORCID: 0000-0003-3174-9949), victoria.stevens@uct.ac.za

Keywords: (4-6 for indexing purposes)

Seismic Hazard, Seismic Risk, Bhutan, Himalayas, Earthquakes

\section{Acknowledgements}

VLS was supported by the Claude Leon Foundation. GH acknowledges the support of the Swiss National Science Foundation (projects PP00P2_157627 and PP00P2_187199). RDR was supported by EPSRC project PREPARE (EP/P028233/1). 
We present the first modern seismic hazard and risk assessment in the Bhutan Himalaya. We used a fault-based probabilistic seismic hazard analysis based on fault locations, slip-rates and paleoseismic earthquake data. We worked with two seismic intensity measures: the peak-ground acceleration (PGA) and Modified Mercalli Intensity (MMI). We extend the hazard analysis to risk by using local building distribution data and making various assumptions about building distribution and fragility. We find, unsurprisingly, that the Main Himalayan Thrust (MHT) is the primary source of hazard, with oblique strike-slip faults cutting across and beneath the Himalaya, and extensional grabens on the northern edge of Bhutan a secondary hazard. The hazard is highest in the southern part of Bhutan where the MHT is shallow, and site conditions lead to amplification of shaking. The risk does not reflect the hazard solely, but also the distribution of exposure, which is concentrated in the cities. We also simulated the $1714 \mathrm{M}_{\mathrm{w}} 8$ earthquake, producing 10,000 possible shakemaps in terms of PGA and MMI; we find that many locations could experience PGA values of over $1 \mathrm{~g}$, and on average, up to $18 \%$ of the Bhutanese population could be affected. Refining the probable frequency of larger events on the MHT in this region, developing local Ground Motion Prediction Equations, creating tailored vulnerability models for typical Bhutanese buildings, and improving the exposure mapping would most improve the hazard and risk results shown here. The existing building code of Bhutan, adopted from the Indian Seismic Zonation of 2002 (BIS-1893, 2002), uses a PGA of $0.36 \mathrm{~g}$ uniformly applied across the entire country. Our study, however, presents a non-uniform hazard level across the country and thus questions the relevancy of the current code of construction practices in the country.

\section{Plain Language Summary}

We assess earthquake hazard in Bhutan, which is high and similar to neighbouring countries. The highest earthquake hazard is in the southern part of the country, where the shaking from a large earthquake would come from shallow depths, and the properties of the soil mean that shaking would be increased even further. If there was a repeat of the large earthquake that occurred in Bhutan in 1714, many locations could experience very high shaking. The high hazard, together with the high vulnerability of several of the typical local building types leads to a very high earthquake risk in terms of building collapse and people affected. Other earthquake-related hazards such as landslides in the hilly regions, and liquefaction in the plains regions, have not been considered here, but would further amplify the consequences.

\section{Introduction}

There have been many large earthquakes along the Himalayan range, including the $1950 \mathrm{M}_{\mathrm{w}} 8.7$ Assam event, which ruptured to within $200 \mathrm{~km}$ east of Bhutan (e.g. Chen and Molnar, 1977; Coudurier-Curveur et al., 2020). Recent events include the 2015, Mw7.8, Gorkha Nepal earthquake, the $2005 \mathrm{M}_{\mathrm{w}} 7.6$, Kashmir India earthquake, and the smaller 2019, $\mathrm{M}_{\mathrm{w}} 5.6$, Kashmir Pakistan earthquake which also caused multiple fatalities and destruction. In 2009, eastern Bhutan experienced an $M_{w} 6.1$ earthquake, with several fatalities, and many thousands affected. Although there have been no recent very large earthquakes in Bhutan (Drukpa, Velasco and Doser, 2006), over the last decades, paleoseismic evidence for coseismic ruptures along the front of the Himalaya with 1 to $13 \mathrm{~m}$ of uplift, suggests that major earthquakes have occurred here. The study of Bollinger et al., 2014 showed the occurrence of at least six surface-rupturing paleo-earthquakes in the past $4500 \pm 50$ years along the Main Frontal 
87 Thrust (MFT) in Nepal and proposed that the return periods $\left(T_{R}\right)$ of such earthquakes probably range between 750

$88 \pm 140$ and $870 \pm 350$ years. Similarly, Le Roux-Mallouf et al., (2020) proposed, from paleoseismological 89 investigations along the MFT in Bhutan (Berthet et al., 2014; Le Roux-Mallouf et al., 2016), a return time of 550 $90 \pm 210$ years, based on the occurrence of at least five events in the past 2600 years.

91 Bhutan (see Fig. 1) spans the Himalaya, from the low-lying Brahmaputra Plain to the high Tibetan Plateau. The 92 Main Himalayan Thrust (MHT), which covers the entire length of the Himalayan Arc, underlies most of Bhutan. 93 Interseismic loading is mainly released by major earthquakes, as the amount of permanent aseismic deformation 94 has been shown to be low (e.g. Stevens \& Avouac, 2015), though there are indications that the fault may be 95 creeping in some locations (Marechal et al., 2016). A recent study has shown that similar to the rest of the 96 Himalayan arc, Bhutan has significant microseismicity (Diehl et al., 2017) and is affected by large earthquakes 97 (Le Roux-Mallouf et al., 2016).

98

There have been no previous Probabilistic Seismic Hazard Analyses (PSHA) focusing on Bhutan, though it is included in a previous study of regional PSHA in South Asia (e.g. Bhatia, Kumar and Gupta, 1999). This previous study used a seismic source area-based model to classify the Himalayan region, with the whole of Bhutan classified as a zone of high hazard. A different method, which combines a few event scenarios but does not perform a complete PSHA and so is considered less reliable and less representative, has coincidentally been published at the same time as our study (Robinson, 2020). Here we use a fault-based model that includes the results from many recent earthquake-related studies of Bhutan and surrounding regions, such as microseismicity and paleoseismic trenching (e.g. Le Roux-Mallouf et al., 2016; Diehl et al., 2017).

Similarly to the PSHA, there have been scarce risk studies focusing on Bhutan. Apart from the hazard component, even if the exposure can be fairly represented, the vulnerability components can rely only on global models. Therefore, given the lack of tailored country-based vulnerability models, only a first-generation probabilistic seismic risk model can be developed.

Here we study both the hazard and the subsequent risk from earthquakes. We first go through the data and methods used, before showing the hazard and risk results of a scenario earthquake, the PSHA analysis, and discussing the assumptions and implications. 


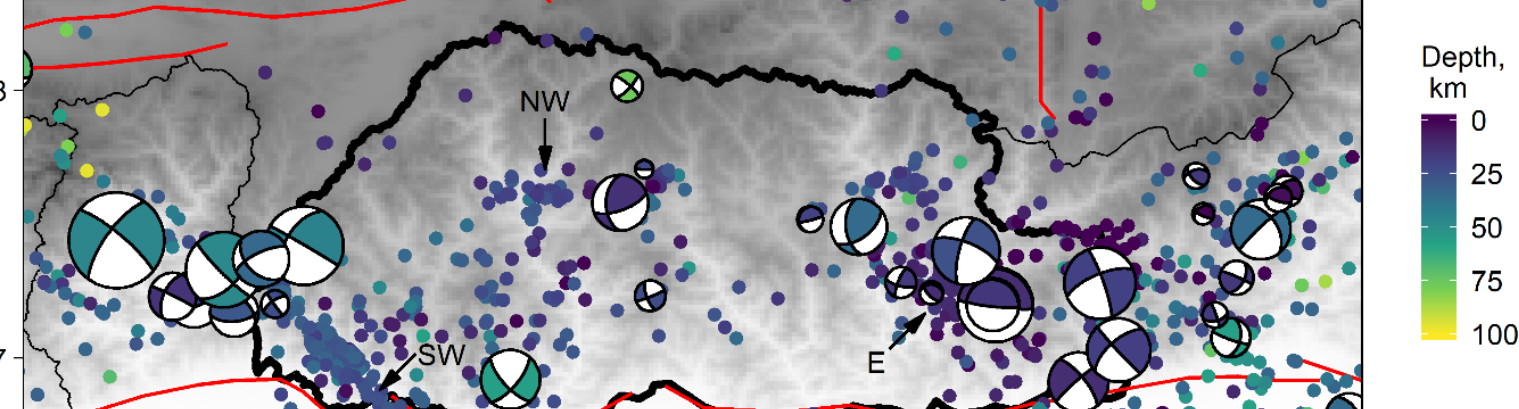

$27-$

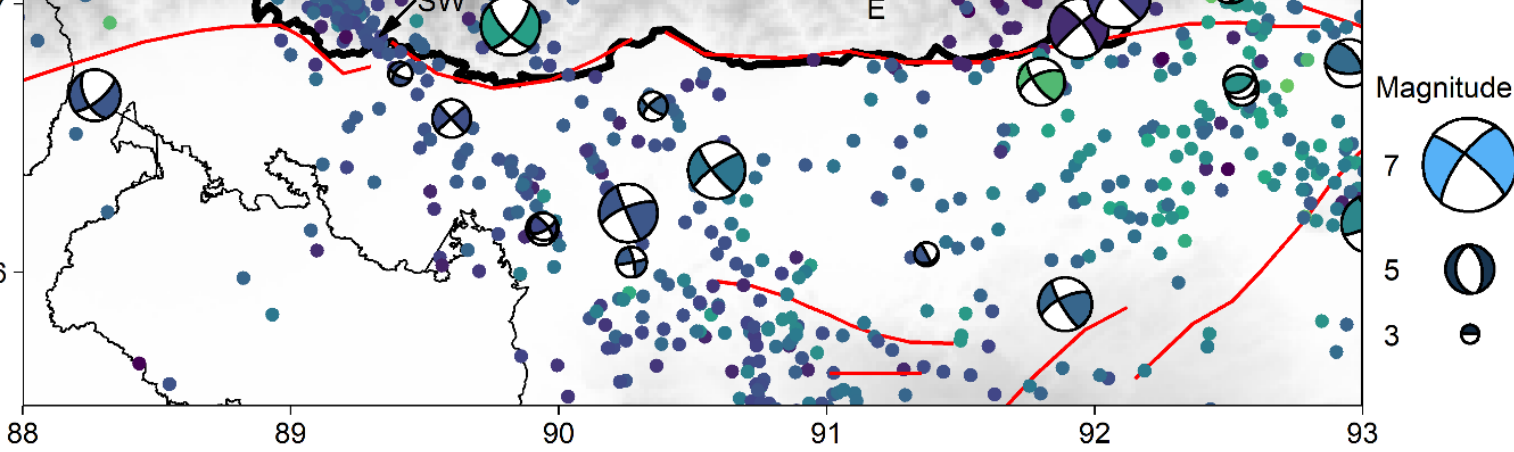

Fig. 1 Geological setting of Bhutan (borders in thick line). Earthquakes and focal mechanisms from the GANSSER (Diehl et al. 2017), the CMT and ANSS catalogs. E = Eastern earthquake cluster, NW =

Northwestern earthquake cluster, SW = Southwestern earthquake cluster. Faults from Styron, Taylor and

\section{Data and Methods}

We use the OpenQuake software (http://openquake.org/) to perform PSHA of Bhutan. Inputs to the model include fault parameters (geometry, maximum earthquake magnitude, and Gutenberg-Richter (GR) relation $a$ and $b$ values (Gutenberg and Richter, 1944)), ground motion prediction equations (GMPEs), and site characteristics (here $\mathrm{V}_{\mathrm{S} 30}$, the average shear-wave velocity in the top 30 meters of the ground, is used).

\subsection{Instrumental Earthquake Catalogs}

Three earthquake catalogs have been used in this study.

\subsubsection{ANSS catalog}

The global ANSS catalog covers the period 1915-2019 AD. We homogenize the magnitude types following the relations by Scordilis, (2006).

\subsubsection{CMT catalog} our study region was recorded in 1979, and the latest in 2018. 


\subsubsection{GANSSER catalog}

We also use a local catalog with nearly 2 years of data from the GANSSER project network (Swiss Seismological Service at ETH Zurich, 2013), published by Diehl et al., (2017). This catalog reveals three regions of enhanced seismicity - in SW Bhutan, NW Bhutan, and eastern Bhutan, shown on Fig. 1.

The NW cluster is situated above the flat and mid-crustal ramp transition of the MHT, as defined by Hauck et al., (1998); Coutand et al., (2014); Le Roux-Mallouf et al., (2015); Singer et al., (2017).

The SW cluster of seismicity aligns NW-SE, striking from Chungthang in NE Sikkim, to Dhubri on the northern edge of the Shillong Plateau in the foreland. This seismicity is consistent with a previously identified seismic cluster ( Velasco et al., 2007), and has been proposed to be a dextral fault zone based on the moment tensor of the 2011 M6.9 Sikkim, India earthquake, which likely belongs to the same structure (Paul et al., 2015; Diehl et al., 2017). It has been named the Dhubri-Chungthang Fault Zone (DCF) by Diehl et al., (2017) (Fig. 2). Most of the earthquakes along the DCF occur in the Indian basement between 20 and $40 \mathrm{~km}$ depth, and the fault has no surface expression.

The eastern cluster is roughly aligned along a sub-horizontal seismogenic structure at about $12 \mathrm{~km}$ depth, consistent with the hypocenter of the $2009 \mathrm{M}_{\mathrm{w}} 6.1$ earthquake, and its probable origin on the MHT, which in this region has the location of the flat portion constrained to be between 9 and $12 \mathrm{~km}$ depth (Marechal et al., 2016).

\subsection{Historical and Paleoseismic Seismicity}

Le Roux-Mallouf et al. (2020) reported several surface-rupturing earthquakes along the MFT in Bhutan. They showed that Bhutan was struck by at least five $M_{w}>7.5$ earthquakes in the past 2,600 years, including two in the past 1,000 years. Based on the study of historical documents, and geological evidence of surface rupture (Hetényi, Le Roux-Mallouf, et al., 2016), the most recent surface-rupturing earthquake to hit Bhutan occurred on the MHT in 1714 AD. The penultimate event, which also ruptured the MHT, and broke the surface along the MFT, is characterized by about $8 \mathrm{~m}$ coseismic uplift and occurred during Medieval times with an inferred magnitude of 8.7-9.1 (Le Roux-Mallouf et al., 2016). They used chronostratigraphic modelling to suggest that the average recurrence interval of surface-rupturing earthquakes is $550 \pm 210 \mathrm{yr}$.

Other faults in the region do not have such a long paleoseismic record, though large earthquakes have been recorded on them e.g. the 1897, Mw8.2 Shillong earthquake in 1897 on the Oldham fault (England and Bilham, 2015) (Fig. 2), and the 1930, $\mathrm{M}_{\mathrm{W}} 7$ Dhubri earthquake, on the Dhubri-Chungthang fault (Gee, 1934). Other faults in the region do not have any record of earthquakes larger than $\mathrm{M}_{\mathrm{W}} 6$.

\subsection{Fault Source Model}

While microseismicity is useful in identifying larger tectonic structures and gives some indication of fault activity, whether the current location and intensity of microseismicity are straight-forwardly indicative of the probability of future large earthquakes at that location is debated. Since a large (e.g. $\mathrm{M}_{\mathrm{W}} 8.5$ ) earthquake could rupture hundreds of kilometres along the Himalaya, a rupture that started on one side of Bhutan could propagate across the entire country, with the amount of microseismicity in different areas of Bhutan having little influence on this 
large rupture. Numerous active faults can be distinguished in the studied region, and we have used the most significant in this study (Fig. 2) to create a fault-based seismic hazard model.

For the MHT and the Oldham fault, we have estimates of the maximum magnitude $\left(\mathrm{M}_{\mathrm{W}, \max }\right)$; however, for the other fault sources, we calculate $\mathrm{M}_{\mathrm{W} \text {,max }}$ from the potential rupture area. We use the length and width (partly following Grujic et al., (2018) values) of largest possible rupture plane (with uncertainties) and assume the ratio between average slip and length is $2 \times 10^{-5}$ (e.g. Scholz, 2002; Wells \& Coppersmith, 1994) to find $\mathrm{M}_{\mathrm{W}, \max }$ for each rupture. Then, assuming the moment build-up rate from slip-rate and rupture plane area, allowing for 10-20\% aseismic moment release, assuming a $b$ value of 0.8-1 (the $b$ value from instrumental catalogs is on the lower side of 1 (Diehl et al., 2017)), and that earthquakes follow the truncated GR distribution, we find the $a$ value and recurrence time of the maximum sized earthquake. The inputs to OpenQuake are discrete $a, b$ and $\mathrm{M}_{\mathrm{W}, \max }$ values, along with their probabilities. The values used are listed in Table 1.

The following paragraphs discuss in more detail the different fault sources.

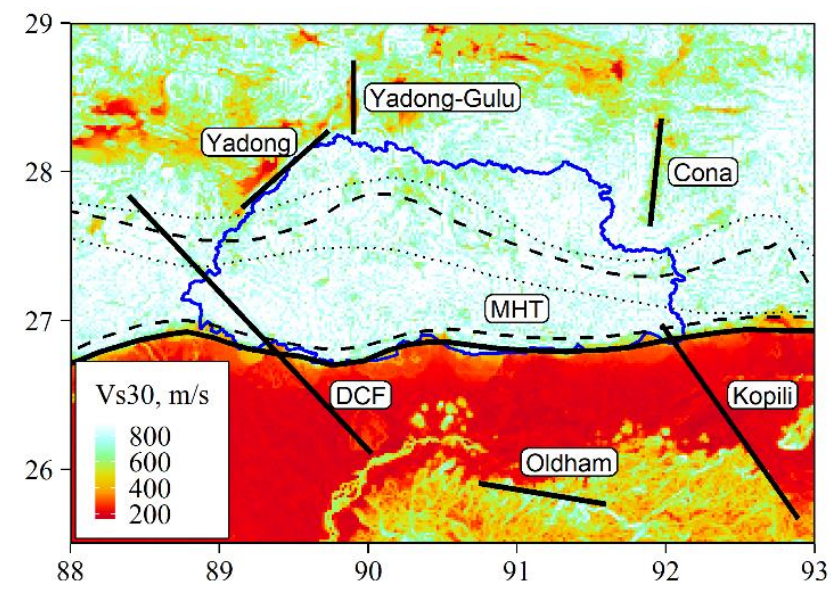

Fig. 2 Inputs to the model. The background color is the VS30 map, with values from the USGS Global V V30 model (Wald and Allen, 2007). Solid lines show the surface traces or projections of fault sources used in the hazard model. For the MHT, the transition between the narrow steep frontal ramp and the flat underlying most of Bhutan is shown by the southern dashed line. The northern dashed and dotted lines show where the coupling (from Stevens \& Avouac, 2015) reaches 0.6 \pm 0.15 respectively. MHT = Main Himalayan Thrust. DCF $=$ DhubriChungthang fault zone.

\subsubsection{The Main Himalayan Thrust (MHT)}

The MHT is treated as homogeneous and continuous across Bhutan. There are variations in seismicity, and structural segmentation along the Himalaya has been proposed (Hetényi, Cattin, et al., 2016); however, Bhutan falls on a single segment. Moreover, globally, past ruptures have been shown to rupture through multiple 'segments' (e.g. the 2004 Sumatra and 2011 Tohoku-Oki events), and studies in California have also shown that earthquakes can rupture through multiple segments (Field et al., 2014). We do not yet have clear evidence from the Himalaya as to whether a large earthquake could cross 'segment boundaries'.

The long-term velocities across the fault in the region of Bhutan are roughly 17-19 mm/yr (Stevens and Avouac, 2015; Marechal et al., 2016) and evidence for past megathrust earthquakes here have been provided by other recent studies (Berthet et al., 2014; Hetényi, Le Roux-Mallouf, et al., 2016; Le Roux-Mallouf et al., 2016; Le 
Roux-Mallouf et al., 2020). Based on paleoseismic studies, and evidence of large earthquakes elsewhere on the MHT, we assume that the maximum magnitude is $8.9 \pm 0.1$.

199

200

201

202

203

204

205

206

207

208

209

210

211

212

213

214

215

The MHT is modelled as steeply dipping at $30^{\circ}$ from the surface trace down to $5 \mathrm{~km}$, then dipping gently under much of Bhutan. It has been noted that the location of the crustal ramp and the limit of the locked section of the MHT is further north in western Bhutan than eastern Bhutan (e.g. Le Roux-Mallouf et al., 2015; Marechal et al., 2016; Stevens \& Avouac, 2015). We use the interseismic coupling contour value of $0.6 \pm 0.15$ from Stevens \& Avouac, (2015) to limit the northern extent of seismogenic rupture on the MHT, and assume that this is at $15 \mathrm{~km}$ depth. This agrees with the wider locked section in western Bhutan, and the narrower, 60-km wide MHT in Arunachal Pradesh to the east of Bhutan based on the geological cross-section proposed by Yin, (2006).

There is evidence that some areas of the MHT near the surface trace in eastern Bhutan may be creeping (Marechal et al., 2016), but we do not account for this in the model. We allow 10-20\% of seismic moment accumulation on the MHT to be released aseismically (similarly for other faults), though do not account explicitly for the potential lower moment accumulation rate in eastern Bhutan as this falls within the uncertainty of our modelling. Moment build-up rate on the MHT in the region of Bhutan was calculated from the coupling model and long-term velocities of Stevens \& Avouac, (2015).

We show instrumental and paleoseismic catalogs for the Bhutan region in Fig. 3, along with the moment conservation area which shows the relationship between recurrence time and maximum magnitudes if they were to balance the seismic moment budget. The shaded area between the straight lines shows the ab-space that is sampled in our model, with the lower limit at $\mathrm{M}_{\mathrm{W}} \geq 5$ since this is the smallest earthquake considered here.

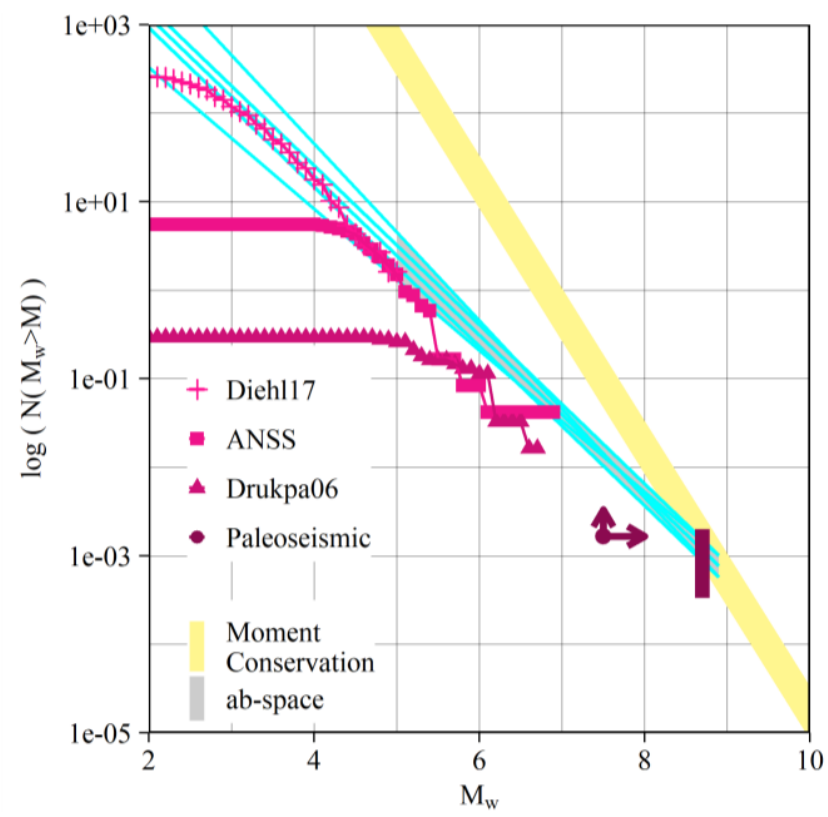

Fig. 3 GR plot of earthquakes on the MHT. The shaded moment conservation area shows the combination of recurrence times and maximum magnitude earthquakes needed to balance the moment budget. Straight cyan lines show different $\mathrm{a}$ and $\mathrm{b}$ combinations used as inputs to the model, with the shaded ab-space area important for the hazard results since only earthquakes $\mathrm{M}_{\mathrm{W}} \geq 5$ are considered in the model. Diehl17 from Diehl et al., (2017), ANSS ( https://earthquake.usgs.gov/data/comcat/), Drukpa06 from Drukpa, Velasco, and Doser, (2006). 

Earthquake in Bhutan, with an uncertain recurrence time, from Le Roux-Mallouf et al., (2016).

\subsubsection{The Dhubri-Chungthang fault zone (DCF)}

227

Located south-west of Bhutan, the DCF is a $250 \mathrm{~km}$ long, NW-SE striking fault zone connecting the Sikkim Himalaya with the Shillong Plateau in the foreland (Diehl et al., 2017). Diehl et al., (2017) propose that the depth distribution of seismicity within the DCF suggests that the seismogenic portion is limited to mid and lower crustal levels, from $15 \mathrm{~km}$ beneath the foreland and deepening to $40 \mathrm{~km}$ and more beneath the Himalaya. The block model of Vernant et al. (2014) predicts around $1 \mathrm{~mm} / \mathrm{yr}$ of dextral slip along the DCF. The largest earthquake recorded with a probable origin on this fault, has a magnitude of $7.1 \pm 0.4$, in 1930 (Gee, 1934).

\subsubsection{The Kopili fault (KF)}

Described by Ray, (2018), the NW-SE Kopili fault is bounded by the Shillong Plateau in the east and corresponds to a major active fault in the Assam valley. Its geometry is mainly constrained by seismicity studies (Kayal et al., 2006; Diehl et al., 2017). Intense seismicity activity is observed down to $\sim 50 \mathrm{~km}$ depth beneath the $170-\mathrm{km}-\mathrm{long}$ Kopili fault. A GPS block model proposed by Vernant et al., (2014) predicts 2-3 mm/yr dextral slip along the Kopili fault, similar to other studies (e.g. Barman et al., 2016).

\subsubsection{The Oldham fault $(\mathrm{OF})$}

Proposed first by Oldham, (1899), England \& Bilham, (2015) constrain the location and slip rate of the Oldham fault, though others question its existence (e.g. Morino et al., 2014). The surface trace strikes WNW-ESE, with length estimates of 70 to $100 \mathrm{~km}$. The fault plane dips $\sim 40^{\circ}$ to the south, with the 1897 earthquake rupturing from roughly $45 \mathrm{~km}$ to $10 \mathrm{~km}$ depth (Bilham and England, 2001). The 1897 event is the largest earthquake known to have occurred here, with an estimated magnitude of $8.15<\mathrm{M}_{\mathrm{W}}<8.35$ (England and Bilham, 2015). This earthquake had a very large average slip, of roughly $25 \pm 5 \mathrm{~m}$, a lot larger than expected from scaling relationships (e.g. Scholz, 2002; Wells \& Coppersmith, 1994), so the earthquake was much larger than could be estimated from the dimensions of the rupture plane. Because of historical evidence for it, we use the estimation of $8.2 \pm 0.1$ for the maximum earthquake size. The slip rate across this fault is low at $\sim 2.5 \mathrm{~mm} / \mathrm{yr}$ (Vernant et al., 2014; England and Bilham, 2015) meaning the recurrence time for this sized earthquake would be very long, i.e. at least a few thousand years, though this is very uncertain due to the short GPS observation record. Most of the deformation for the Shillong Plateau region is taken up along its southern edge by the Dauki fault, which adds to the uncertainty of the rate across the Oldham fault, though the Dauki fault is too far away from Bhutan to be modelled in this study (Grujic et al., 2018).

\subsubsection{The Yadong Cross Structure (YCS, normal fault)}

Located parallel to Bhutan's northwestern border in southern Tibet, the NE-SW oriented Yadong Cross Structure (YCS in Fig. 2) is described as a major lateral ramp that may control one of the largest along-strike discontinuities of the Himalayan belt (e.g. C. Wu et al., 1998). While this large-scale structural segmentation might control how 
deformation is presently accommodated (Vernant et al., 2014; Le Roux-Mallouf et al., 2015), its depth impact remains poorly studied. While Hauck et al., (1998) suggest that the main structures at depth are offset, the structure has not really been documented to reach deep in the crust. The fault rectangle source is $80 \mathrm{~km}$ long with a width of $20 \mathrm{~km}$, dipping at $60^{\circ}$. The slip rate of this structure is not well known, though must be low or it would show up more in GPS observations, and current seismicity near the structure is also very low. We assume a slip rate of $0.5_{-0.4}^{+0.3} \mathrm{~mm} / \mathrm{yr}$. From the fault dimensions, the physical $\mathbf{M}_{\max }$ would be $7 \pm 0.2$ and from the calculation of a value, the recurrence time would be $900_{-425}^{+1000}$ years.

\subsubsection{The Yadong-Gulu Rift \& Cona Rift}

The Yadong-Gulu and Cona Rifts are both N-S striking extensional grabens situated on the southern Tibetan Plateau, at the northern edge of western and eastern Bhutan respectively.

Extension across the Yadong-Gulu rift from GPS is roughly $2 \pm 0.6 \mathrm{~mm} / \mathrm{year}$, whereas the Cona fault has a much lower extensional rate (Gan et al., 2007). However, earthquakes of M7.5 and M7 occurred in 1806 and 1915 respectively (Wu et al., 2008) on the northern Cona fault. The Cona fault is eastward dipping, while the YadongGulu suture dips west (Wang et al., 2019). We assume a slip rate of $2 \pm 0.6 \mathrm{~mm} / \mathrm{yr}$ and $0.5_{-0.4}^{+0.3} \mathrm{~mm} / \mathrm{yr}$ for the Yadong-Gulu and Cona rifts respectively, for other parameters see Table 1.

\subsubsection{Background Area}

We assume that a maximum magnitude earthquake of $6 \pm 0.2$ could happen anywhere in areas not considered above. We assume that earthquakes of the same size happen in the background area with a frequency of 5\% that of those on the MHT.

Table 1 Source parameters used in the model. $\mathrm{L}=$ Length, $\mathrm{W}=$ Width, $\mathrm{M}, \mathrm{L}, \mathrm{U}=$ mean, lower and upper estimates. $\mathrm{NA}=$ Not Applicable. Yd-Gl=Yadong-Gulu, Bkgr=Background. Values in bold are not calculated, but determined from observations. For details of how $\mathrm{M}_{\max }$ and recurrence time are calculated, see the methods section. The a values are used in combination with $\mathrm{b}$ values $0.9,0.8$ and 1 . To calculate lower and upper $\mathrm{M}_{\mathrm{W} \text {,max }}$, uncertainties of $20 \%$ were assumed for $\mathrm{L}$ and $\mathrm{W}$.

\begin{tabular}{|c|c|c|c|c|c|c|c|c|c|c|c|c|c|c|c|}
\hline \multirow{3}{*}{$\begin{array}{l}\text { Fault } \\
\text { Name }\end{array}$} & \multirow[t]{3}{*}{$\mathbf{L}, \mathbf{k m}$} & \multirow{3}{*}{$\begin{array}{l}\text { W, } \\
\text { km }\end{array}$} & \multicolumn{4}{|c|}{$\mathbf{M}_{\mathbf{W}, \max }$} & \multirow{2}{*}{\multicolumn{3}{|c|}{ Slip Rate, mm/yr }} & \multirow{2}{*}{\multicolumn{3}{|c|}{$\begin{array}{l}\text { Recurrence } \\
\text { time, kyrs }\end{array}$}} & \multirow{2}{*}{\multicolumn{3}{|c|}{$\mathbf{a}$}} \\
\hline & & & \multicolumn{3}{|c|}{ Calculated } & \multirow{2}{*}{ Obs. } & & & & & & & & & \\
\hline & & & $\mathbf{M}$ & $\mathbf{L}$ & $\mathbf{U}$ & & $\mathbf{M}$ & $\mathbf{L}$ & $\mathbf{U}$ & $\mathbf{M}$ & $\mathbf{L}$ & $\mathbf{U}$ & $\mathbf{M}$ & $\mathbf{U}$ & $\mathbf{L}$ \\
\hline MHT & $2500^{\mathrm{a}}$ & $100^{\mathrm{a}}$ & 8.9 & 8.8 & 9 & $9^{\mathrm{a}}$ & 19 & 17 & 21 & 1.3 & 0.8 & 2.2 & 4.9 & 5.7 & 4.1 \\
\hline$\overline{\text { DCF }}$ & 252 & 25 & 8.0 & 7.8 & 8.1 & 7 & 1.0 & 0.5 & 1.5 & 10 & 5.4 & 17 & 3.2 & 3.9 & 2.5 \\
\hline Kopili & 171 & 25 & 7.8 & 7.6 & 7.9 & NA & 2.5 & 1.5 & 3.5 & 2.9 & 1.5 & 4.9 & 3.6 & 4.2 & 2.9 \\
\hline Oldham & 87 & 54 & 8.1 & 8.0 & 8.2 & 8 & 3.3 & 2.5 & 4.1 & 5.7 & 3.6 & 9.6 & 3.5 & 4.2 & 2.8 \\
\hline Yadong & 77 & 20 & 7.3 & 7.1 & 7.4 & NA & 0.5 & 0.1 & 0.8 & 9.5 & 4.9 & 16 & 2.6 & 3.2 & 2.0 \\
\hline Cona & 89 & 20 & 7.3 & 7.1 & 7.4 & $7.5^{\mathrm{b}}$ & 0.5 & 0.1 & 0.8 & 9.5 & 5.0 & 16 & 2.6 & 3.2 & 2.0 \\
\hline Yd-GI & 55 & 20 & 7.0 & 6.8 & 7.2 & NA & 2.0 & 1.4 & 2.6 & 0.9 & 0.5 & 1.9 & 3.3 & 3.9 & 2.8 \\
\hline Bkgr & NA & NA & 6.0 & 5.8 & 6.2 & NA & NA & NA & NA & 0.1 & 0.1 & 0.4 & 3.4 & 4.2 & 2.6 \\
\hline
\end{tabular}

${ }^{a}$ From the entire length of the Himalaya. ${ }^{b}$ From the northern part of Cona graben (Wu et al., 2008). 


\subsection{Ground-Motion/Intensity Prediction Equations (GMPEs/IPEs) and Vs30}

No specific GMPEs have been developed for the Himalayan Region (e.g. Stevens, Shrestha and Maharjan, 2018). We use models designed for global use. In this analysis, we treat the MHT as a subduction interface zone, and other faults and areas as active shallow crust.

\subsubsection{PGA}

For the subduction zone interface, we use three GMPEs with equal probability - two developed specifically for subduction zones (BCHYDRO, (Abrahamson, Gregor and Addo, 2016) and ZH06, (Zhao et al., 2006)), and one for active shallow crust (BSSA14, (Boore et al., 2014)). BSSA14 was shown to be a reasonable approximation to the damage caused by the 2015 Gorkha Nepal earthquake (Asimaki et al., 2017). For active shallow crust we use Chiou \& Youngs, (2014) and BSSA14, both developed for global use, in equal probability.

These GMPEs all require VS30 values. VS30 (the average shear-wave velocity to $30 \mathrm{~m}$ depth) is used as a proxy for site effects in most GMPEs. In Bhutan, there are no local measurements, so we use values from the USGS Global $V_{\mathrm{S} 30}$ model (see Fig. 2), which is based on the correlation between $\mathrm{V}_{\mathrm{S} 30}$ and topographic slope (Wald and Allen, 2007).

\subsubsection{MMI}

For modified Mercalli intensity (MMI) results, we use one intensity prediction equation (IPE), developed by Allen et al. (2012) to be globally applicable in crustal regions. In general, the application of site amplification factors for IPEs has been limited, and there are few studies showing that including site factors leads to a statistically significant reduction in uncertainties for IPEs (Cua et al., 2010; Allen, Wald and Worden, 2012). We do not use $\mathrm{V}_{\mathrm{S} 30}$ values in this case.

\subsection{Exposure}

We quantified the exposure in terms of the number of people, number and typology of buildings. In Bhutan, the population is just under 1 million; its distribution is hereafter presented and discussed. The exact number of buildings is not available; on the other hand, percentages of different building typologies and occupancy rates are available.

\subsubsection{Population}

The number of people at the national level is quantified using the WorldPop database (Stevens et al., 2015; Tatem, 2017). This database was created by combining demographic and geographic data, and it provides high-resolution population maps (100 m resolution) for 2020. In the absence of more detailed official data, WorldPop can be considered the best freeware option. For developing countries, WorldPop is preferable to other available resources (Goda et al., 2016) such as LandScan (Dobson et al., 2000) or GPW4 (CIESIN, 2016).

Fig. 4(a) shows the population density of Bhutan in 2020. The population density is very low in general and only reaches higher values in the proximity of major cities such as Thimphu, the capital, Phuentsholing, Bhutan's commercial hub, and Paro, with the only international airport. However, Indian territories adjacent to Bhutan host a higher concentration of population. Figs. 4(b), (c), and (d) show detail for the three major cities that are studied 

constructed on the MFT, the surface trace of the MHT.
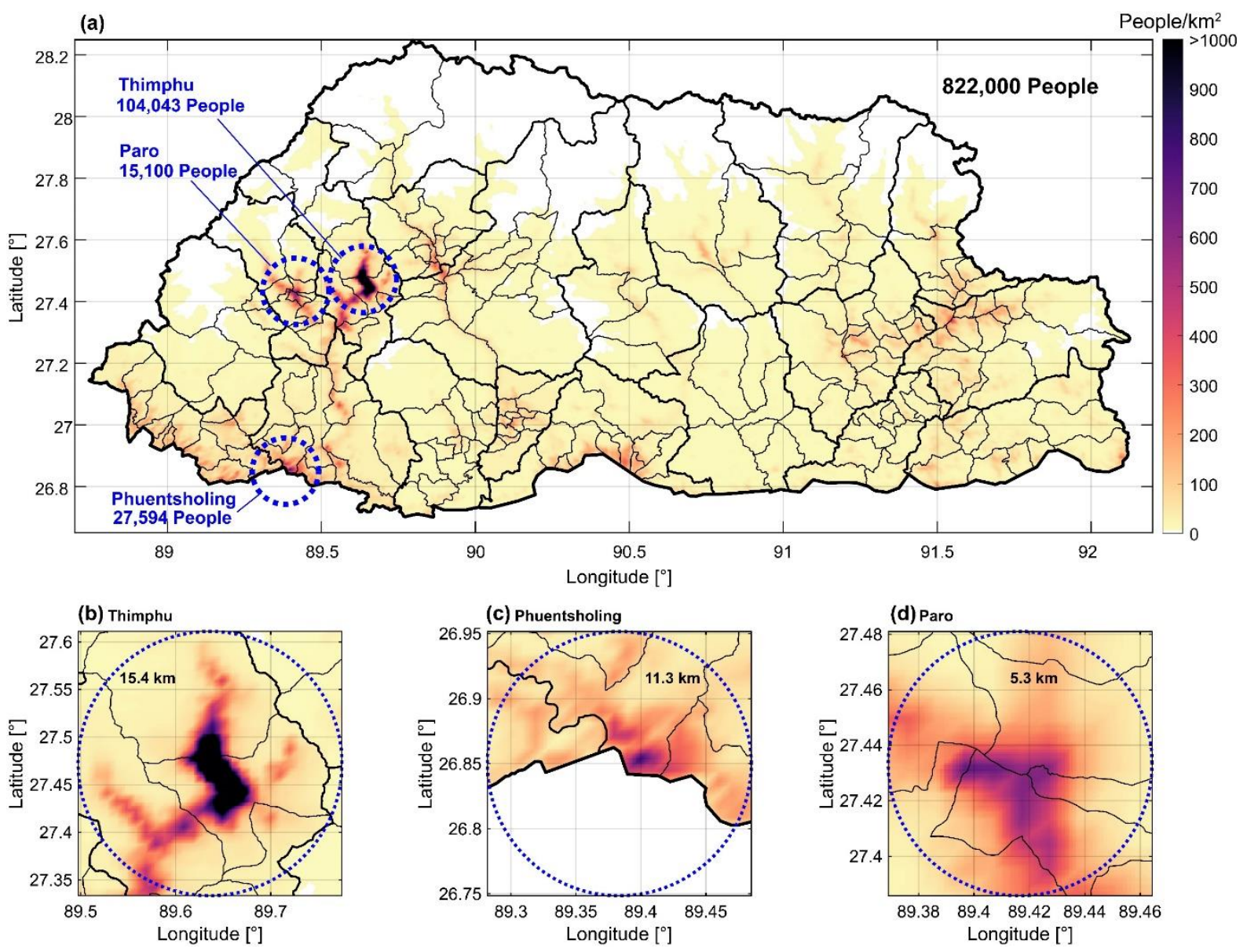

Fig. 4 (a) Population distribution in Bhutan in 2020. Population distribution in (b) Thimphu, (c) Phuentsholing, and (d) Paro.

For each city, the population is quantified by counting the people enclosed in circular domains. The centre of each circular area has coordinates $89.6361^{\circ} \mathrm{E}-27.4722^{\circ} \mathrm{N}$ for Thimphu (capital), $89.3833^{\circ} \mathrm{E}-26.8500^{\circ} \mathrm{N}$ for Phuentsholing (commercial hub) and $89.4167^{\circ} \mathrm{E}-27.4333^{\circ} \mathrm{N}$ for Paro (airport). The radius for each circular domain is defined to have a total number of enclosed people similar to the censuses number, i.e. $15.4 \mathrm{~km}$ for Thimphu, $11.3 \mathrm{~km}$ for Phuentsholing and $5.3 \mathrm{~km}$ for Paro. According to WorldPop, in 2020, the total number of people in Bhutan is 822,000, and the number of people for the cities of Thimphu, Phuentsholing and Paro is about 104,000, 27,600 , and 15,100 , respectively.

\subsubsection{Buildings}

The identification of building typologies is paramount for two reasons: (a) for the selection of proper vulnerability models from literature and (b) for correct quantification of the losses. Two major research projects provide a classification of the building typologies in Bhutan: PAGER (Jaiswal and Wald, 2008) and EQRisk (Lang, Singh and Namgyel, 2013). The EQRisk project studied the Indian subcontinent explicitly, while the PAGER project has a global scale. The two projects have different taxonomies for the classification. Herein, the taxonomy 
proposed by PAGER is adopted. Later, the taxonomy proposed by the European Macroseismic Scale (EMS,

340 Grünthal, 1998) is also used.

341 The PAGER project provides a single classification for both urban and rural residential/non-residential 342 environments. Six building typologies are identified in Bhutan: $45 \%$ are unreinforced fired-brick masonry (UFB), $34330 \%$ are adobe-block walls (A), 11\% are informal constructions (INF), 10\% are rubble-stone masonry (RS), 3\% 344 are reinforced concrete $(\mathrm{C})$ and $1 \%$ are wooden structures $(\mathrm{W})$. The INF buildings generally do not conform to 345 engineering standards. Fig. 5(a) shows the distribution of the different building typologies graphically.

346 The EQRisk project classifies the buildings in Bhutan into 10 categories. According to a more straightforward 347 description, mainly based on the material of the bearing structure, five building typologies are identified: rammed348 earth wall structures (RE), wattle and daub structures (W5), ductile reinforced concrete moment frame with or 349 without infill (C1), adobe-block, mud-mortar, wood roof and floors (A1), and confined concrete blocks with 350 cement mortar, new construction (RM3). Unfortunately, EQRisk does not provide the distribution of the structural 351 typologies. Therefore, a detailed survey conducted by the Bhutanese Department of Engineering Services of the 352 Ministry of Works \& Human Settlement for three districts (dzongkhags), namely Paro, Punakha and Trashi 353 Yangtse, is used. Fig. 5(b) shows the distribution of the different building typologies graphically.

(a)

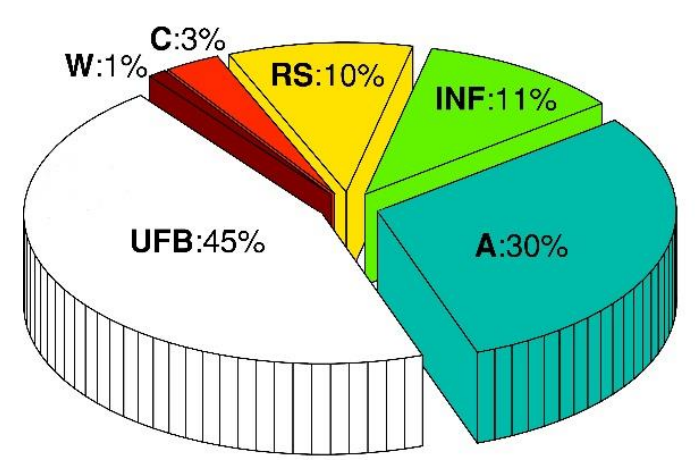

(b)

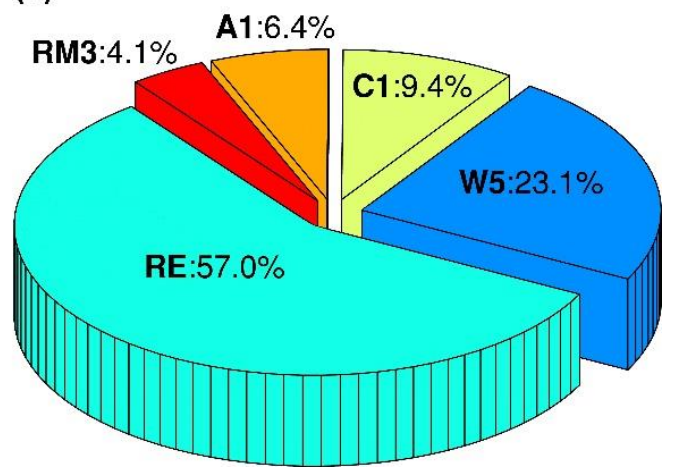

Fig. 5 (a) PAGER classification and distribution of buildings. (b) EQRisk classification and governmental-based distribution of the buildings. See Table 2 for abbreviation descriptions and Fig. 6 for photos. 
(a)

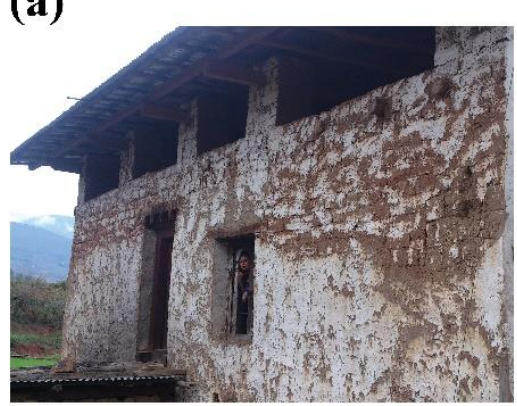

(d)

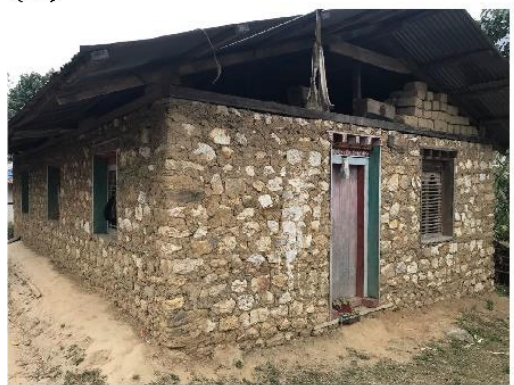

(g)

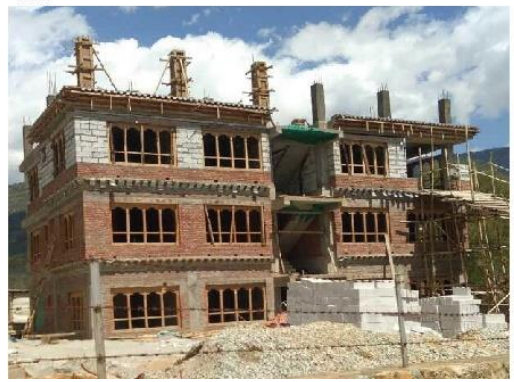

(b)

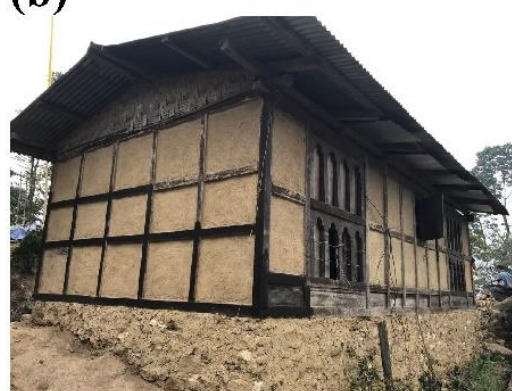

(e)

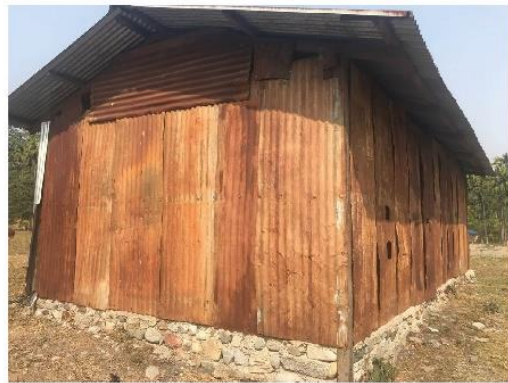

(h)

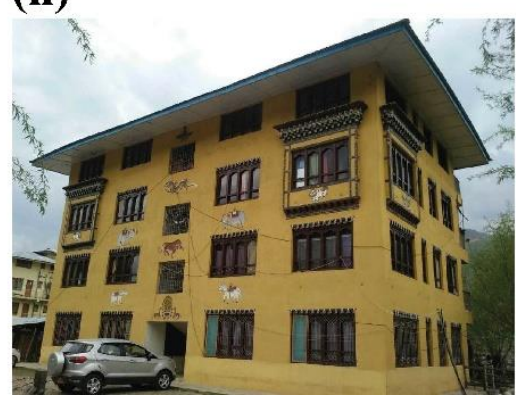

(c)

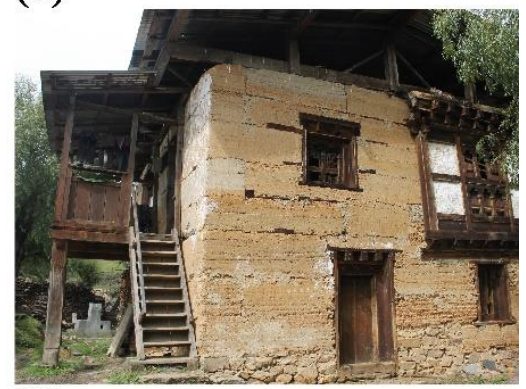

(f)

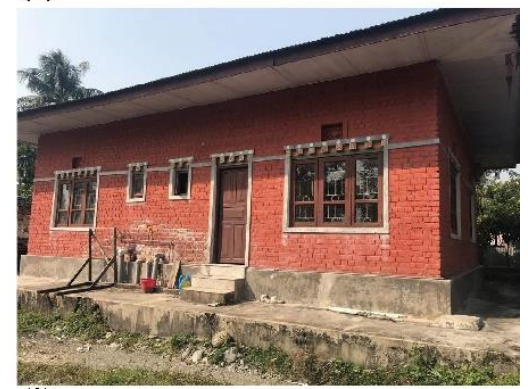

(i)

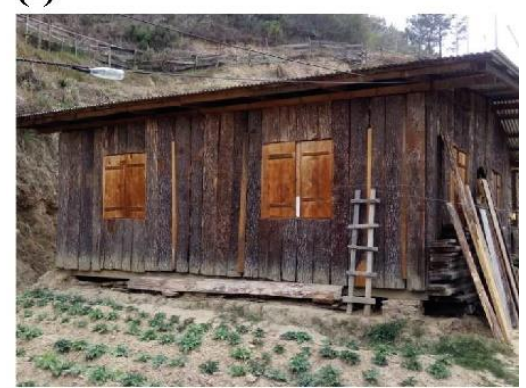

Fig. 6 Building typologies in Bhutan. (a) Adobe, (b) Wattle/Daub, (c) Rammed earth, (d) Stone masonry, (e) Informal, (f) Unreinforced fired-brick masonry, (g-h) Pre-code/high-ductility reinforced concrete, (i) Wood. Photos courtesy of the Department of Engineering Services, Ministry of Works and Human Settlement, Bhutan.

The previous typology classification can also be represented using the EMS building categorisation. Specifically, the PAGER categories A, A1, W5, RE, RS and INF can be grouped under the EMS category A, where A stands for adobe (earth bricks), fieldstone and rubble stone buildings. The PAGER category UFB corresponds to the EMS category B, i.e. simple-stone or unreinforced masonry. The PAGER categories C and RM3 correspond to the EMS category $\mathrm{C}$, which is representative of unreinforced masonry with reinforced concrete floors and reinforced concrete structures with frames without earthquake-resistant design. The PAGER category C1 corresponds to the EMS category E, i.e. reinforced concrete buildings with a high level of earthquake-resistant structures. Finally, the PAGER category W corresponds to the ENS category D2, indicative of timber structures. Table 2 summarises the two adopted taxonomies listing the structural typologies identified by PAGER and EQRisk. 
Table 2 Structural typologies according the PAGER and EMS taxonomies

\begin{tabular}{|c|c|c|c|}
\hline \multicolumn{2}{|r|}{ PAGER taxonomy } & \multicolumn{2}{|r|}{ EMS taxonomy } \\
\hline & Description & & Description \\
\hline $\mathbf{A}$ & $\begin{array}{l}\text { Adobe blocks (unbaked sundried mud block) } \\
\text { walls }\end{array}$ & \multirow{6}{*}{ A } & \multirow{6}{*}{ Weak masonry } \\
\hline A1 & Adobe block, mud mortar, wood roof and floors & & \\
\hline W5 & $\begin{array}{l}\text { Wattle and Daub (Walls with bamboo/light } \\
\text { timber log/reed mesh and post). }\end{array}$ & & \\
\hline $\mathbf{R E}$ & $\begin{array}{l}\text { Rammed Earth/Pneumatically impacted } \\
\text { stabilized earth }\end{array}$ & & \\
\hline $\mathbf{R S}$ & Rubble stone (field stone) masonry & & \\
\hline INF & Informal constructions & & \\
\hline UFB & Unreinforced fired brick masonry & B & Unreinforced load-bearing masonry \\
\hline $\mathbf{C}$ & Reinforced concrete & \multirow{2}{*}{$\mathbf{C}$} & \multirow{2}{*}{$\begin{array}{l}\text { Structural Masonry; pre-code reinforced } \\
\text { concrete }\end{array}$} \\
\hline RM3 & Reinforced masonry & & \\
\hline C1 & $\begin{array}{l}\text { Ductile reinforced concrete moment frame with } \\
\text { or without infill }\end{array}$ & $\mathbf{E}$ & $\begin{array}{l}\text { Steel frame - High-ductility reinforced } \\
\text { concrete frames }\end{array}$ \\
\hline $\mathbf{W}$ & Wood & D2 & Timber frames \\
\hline
\end{tabular}

377

According to the Department of Engineering Services of the Ministry of Works \& Human Settlement, a weighted (on the building typology distribution) average of 8.16 people for building can be assumed for entire Bhutan, independent of the building typology. The breakdown of the average per building typology is 7.24 for RE, 5.88 for W5, 20.81 for C1, 5 for A1 and 7.30 for RM3. As suggested by Goda et al. (2016), to map the population data to building data, the number of people is divided by the average occupancy. Both the average and specific density occupancy for the different typologies are used in the following.

\subsection{Vulnerability}

We use four vulnerability models to predict the number of buildings that may collapse under seismic shaking: (1) Jaiswal, Wald and D'Ayala (2011), (2) So and Spence (2013), (3) Polidoro and Spence (2015), and (4) FoulserPiggott, Bowman and Hughes (2020). The first model adopts the PAGER classification; the other three models are based on the EMS classification scheme. All four models are derived from global databases of structural damages observed in the aftermath of seismic events, and provide the probability of collapse conditioned on a specific value of MMI, which is a macroseismic intensity measure (IM).

Fig. 7 shows the vulnerability models proposed by Jaiswal, Wald and D'Ayala (2011) for the building classifications proposed by PAGER and EQRisk. The EQRisk classification is very detailed; however, vulnerability models for some specific classes are not available, and therefore some approximation is needed. Specifically, for the category A1, the same model as for A is used. For the category W5 the same model as for W is used. For RE, the vulnerability model for mud structures - is used. For UFB5, the UFB model is used. Finally, for RM3, the reinforce masonry model RM is used. Equation 1 shows the functional form of the Jaiswal, Wald and D'Ayala (2011) vulnerability model; the parameters (i.e. $p, q$, and $r$ ) for each structural typology are listed in Table 3. 
(a)

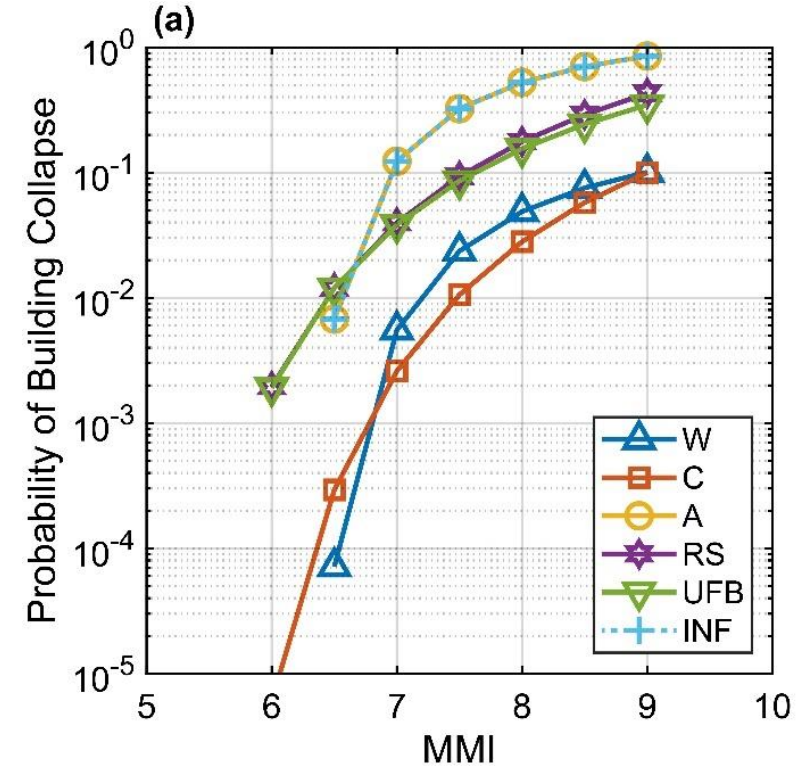

(b)

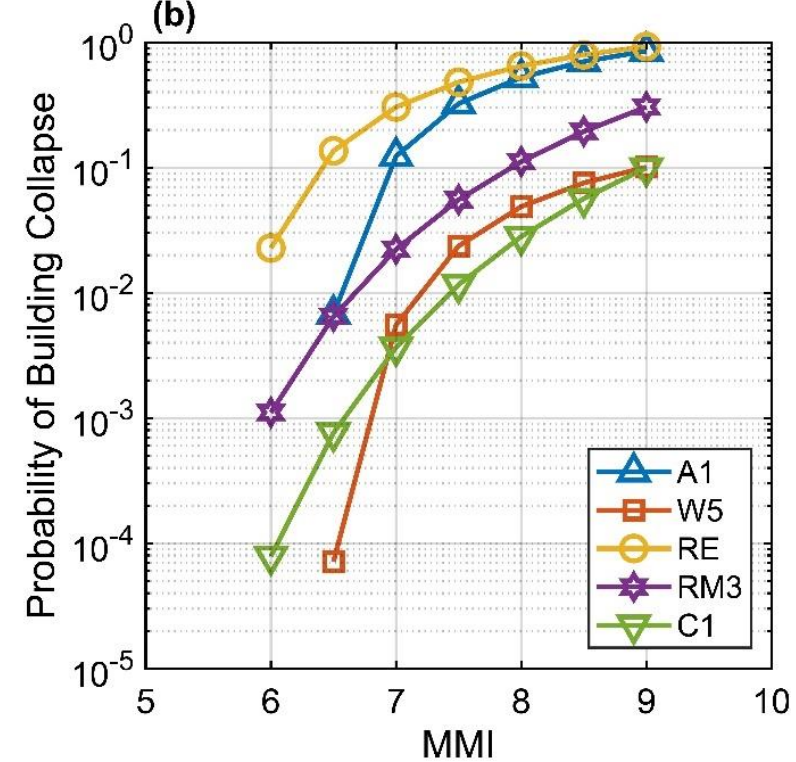

400 401

402

403

404

405

406

407

408

409

410

Fig. 7 Jaiswal et al. (2011) vulnerability models: (a) PAGER classification and (b) EQRisk classification with PAGER taxonomy.

$$
P(\text { Collapse } \mid M M I)=p \cdot 10 \frac{q}{M M I-r}
$$

Table 3 Parameters for vulnerability models according to Jaiswal et al. (2011)

\begin{tabular}{|c|c|c|c|c|c|c|c|}
\hline Class & $\mathbf{p}$ & $\mathbf{q}$ & $\mathbf{r}$ & $\mathbf{C l a s s}$ & $\mathbf{p}$ & $\mathbf{q}$ & $\mathbf{r}$ \\
\hline $\mathbf{W}$ & 0.43 & -1.89 & 6 & $\mathbf{A 1}$ & 2.24 & -1.26 & 6 \\
\hline $\mathbf{C}$ & 6.5 & -7.78 & 4.71 & $\mathbf{W 5}$ & 0.43 & -1.89 & 6 \\
\hline $\mathbf{A}$ & 2.24 & -1.26 & 6 & $\mathbf{R E}$ & 2.55 & -1.68 & 5.18 \\
\hline RS & 14.58 & -7.59 & 4.04 & $\mathbf{R M 3}$ & 23.53 & -10.04 & 3.68 \\
\hline UFB & 7.09 & -6.21 & 4.26 & $\mathbf{C 1}$ & 21.59 & -12.29 & 3.74 \\
\hline INF & 2.24 & -1.26 & 6 & & & & \\
\hline
\end{tabular}

Figs. 8(a), (b) and (c) and Table 4 show the vulnerability models proposed by So and Spence (2013), Polidoro and Spence (2015), and Foulser-Piggott et al. (2020), respectively. The three models refer to EMS taxonomy. Equation 2 shows the functional form of the So and Spence (2013) vulnerability model; Equation 3 shows the functional form for the other two vulnerability models. Polidoro and Spence (2015) provided two different sets of parameters; here we use the averaged vulnerability curves, see Fig. 8(b). 

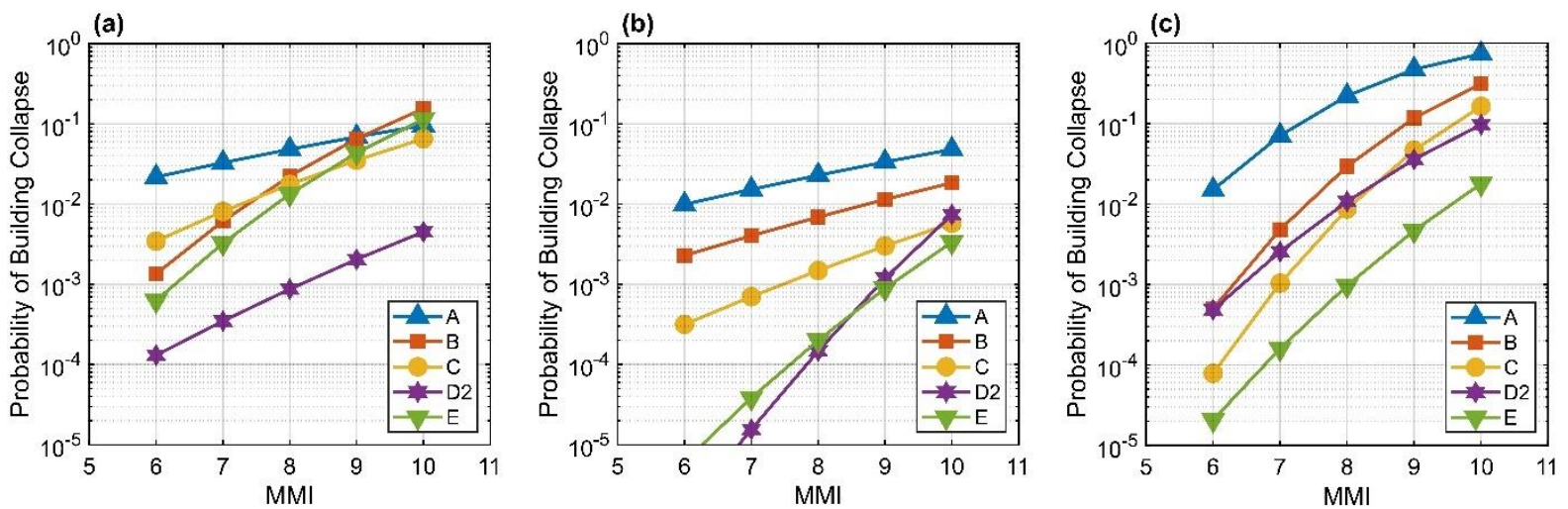

411

Fig. 8 Vulnerability models according to (a) So and Spence (2013), (b) Polidoro and Spence (2015), and (c) Foulser-Piggott et al. (2020), as a function of EMS taxonomy.

$$
\begin{gathered}
P(\text { Collapse } \mid M M I)=\Phi(\alpha \cdot M M I+\beta) \\
P(\text { Collapse } \mid M M I)=\Phi\left(\alpha \cdot M M I-\alpha \cdot I_{0}\right)
\end{gathered}
$$

In equations 2 and $3, \Phi(\cdot)$ is the standard normal distribution function.

Table 4 Parameters for vulnerability models according to So and Spence (2013), Polidoro and Spence (2015), and Foulser-Piggott, Bowman and Hughes (2020).

\begin{tabular}{|c|c|c|c|c|c|c|c|c|}
\hline & \multicolumn{2}{|c|}{ So and Spence } & \multicolumn{4}{|c|}{ Polidoro and Spence } & Foulser-Piggott et al. \\
\hline Class & $\boldsymbol{\alpha}$ & $\boldsymbol{\beta}$ & $\boldsymbol{\alpha}$ & $\mathbf{I}_{\mathbf{0}}$ & $\boldsymbol{\alpha}$ & $\mathbf{I}_{\mathbf{0}}$ & $\boldsymbol{\alpha}$ & $\mathbf{I}_{\mathbf{0}}$ \\
\hline $\mathbf{A}$ & 0.178 & -3.087 & 0.16 & 19.78 & 0.18 & 19.92 & 0.7 & 9.1 \\
\hline $\mathbf{B}$ & 0.496 & -5.976 & 0.18 & 21.21 & 0.2 & 20.86 & 0.7 & 10.7 \\
\hline $\mathbf{C}$ & 0.297 & -4.483 & 0.22 & 21.19 & 0.23 & 21.3 & 0.7 & 11.4 \\
\hline $\mathbf{D 2}$ & 0.26 & -5.211 & 0.67 & 13.42 & 0.47 & 15.68 & 0.5 & 12.6 \\
\hline $\mathbf{E}$ & 0.505 & -6.256 & 0.43 & 16.03 & 0.39 & 17.4 & 0.5 & 14.2 \\
\hline
\end{tabular}

The combination of the data in terms of exposure and vulnerability leads to the identification of four potential models:

M1: Vulnerability curves according to Jaiswal et al. (2011) and exposure distribution according to the PAGER project;

M2: Vulnerability curves according to Jaiswal et al. (2011) and exposure distribution according to the EQRisk project and governmental data;

M3: Vulnerability curves according to So and Spence (2013), Polidoro and Spence (2015), and FoulserPiggott et al. (2017), and exposure distribution according to the PAGER project;

M4: Vulnerability curves according to So and Spence (2013), Polidoro and Spence (2015), and FoulserPiggott et al. (2017), and exposure distribution according to the EQRisk project and governmental data.

The three vulnerability models of So and Spence (2013), Polidoro and Spence (2015), and Foulser-Piggott et al. (2017) are first used together and eventually averaged; this is because they are based on the same progressively improved database of post-earthquake observed damages. 


\subsection{Risk}

\subsubsection{Scenario-based Risk assessment}

The annual probability of exceedance of a specific loss can be computed according to Equation 4 (De Risi, Penna and Simonelli, 2019). In the following, the variables in capital and lower-case letters represent the generic random variable and its specific value.

$$
P(L \geq l)=\sum_{i=1}^{N} \sum_{j=1}^{K} \rho_{j} \iint P_{i j}(L \geq l \mid d s) \cdot f_{i j, D S \mid I M}(d s \mid i m) \cdot f_{i}(i m) \cdot|\mathrm{d} d s| \cdot|\mathrm{d} i m|
$$

Where $P(L \geq l)$ is the probability that the earthquake loss $L$ for the $i$-th cell of the analysis grid exceeds a specific threshold $l . N$ is the number of cells covering the region of interest. $K$ is the number of models adopted for vulnerability and exposure. In this study $K$ is equal to $4 . \rho_{\mathrm{j}}$ is the belief-based weight for the considered models; if all the models are considered equivalent $\rho_{\mathrm{j}}$ are all equal to $1 / K$. The variables $I M$ and $D S$ are the seismic intensity measure and the damage state of the considered system, respectively. In this study, IM is the MMI, and the DS is the building collapse. The term $f_{i}(\mathrm{im})$ is the probability density function of the $I M$ and is herein calculated using a stochastic earthquake scenario (Miano et al., 2016). $f_{i j, D S \mid I M}(\mathrm{ds} \mid \mathrm{im}$ ) is the seismic vulnerability function presented in section 2.6 in this study, it represents the probability of attaining collapse for a given intensity measure. Finally, $P_{i j}(L \geq l \mid d s)$ is the earthquake loss function that that provides the amount of experienced loss if a given damage state is attained; in this study, the loss is equal to $100 \%$ of the exposure if the collapse is experienced and $0 \%$ otherwise. The integral presented in Equation 4 is solved using a standard Monte Carlo simulation framework.

\subsubsection{PSHA-based Risk assessment}

The risk is the convolution of hazard, vulnerability and exposure. The procedure we use here was also successfully used for other hazards (De Risi et al., 2013; De Risi et al., 2018). The vulnerability and exposure models are presented earlier in sections 2.5 and 2.6; herein, the results obtained using the four exposure-vulnerability models are averaged. The risk convolution consists of three main steps. Firstly, the vulnerability models and the hazard are convoluted together in order to derive the mean annual rate of exceedance $\left(\lambda_{L S}\right)$ of a specific limit state (LS, the collapse in this study):

$$
\lambda_{L S}=\int P(L \geq l \mid i m) \cdot|\mathrm{d} \lambda(i m)|
$$

where $P(L \geq l \mid i m)$ is one of the vulnerability curves for the limit state LS and represents the probability of exceeding the limit state LS for a specific intensity measure im. Finally, $\lambda(\mathrm{im})$ denotes hazard curves in terms of the mean annual rate of exceedance of a given intensity measure. Secondly, assuming a Poissonian interarrival time for the events, the probability of exceeding a limit state $P_{L S}(t)$ in a given time $t$ is:

$$
P_{L S}=1-\exp \left(-\lambda_{L S} \cdot t\right)
$$

In general, the Expected Annual Loss (EAL) is of interest; therefore, $t$ is chosen equal to 1 year. Third, for the case of a single limit state (i.e. the collapse in this study), the EAL can be calculated as a function of the $P_{L S}$ as: 


$$
E A L=P_{L S} \cdot E
$$

where $E$ is the value of the exposed asset, and it is either the number of buildings for each cell of the grid or the number of people affected by the structural collapse of the building in which they live in.

\section{Scenario Model}

We look at the shaking predicted from an earthquake scenario based on the earthquake of 1714, which had a magnitude of roughly 8 (Hetényi, Le Roux-Mallouf, et al., 2016). The geometry of the rupture plane we used is loosely based on that of Hetényi, Le Roux-Mallouf, et al. (2016) and can be seen in Fig. S1 in Online Resource 1 .
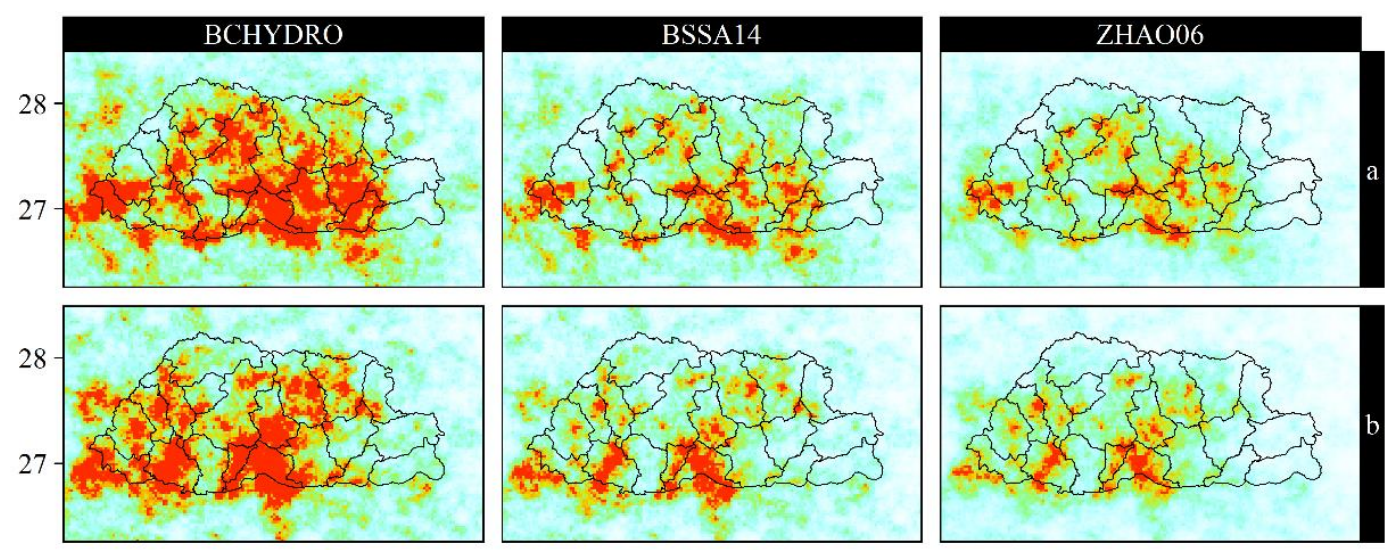

PGA (g)
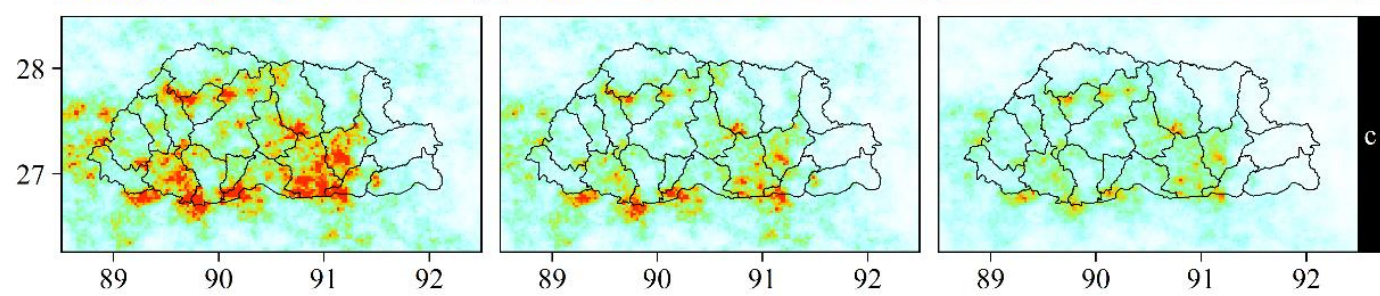

Fig. 9 Scenario hazard results. PGA (g) for various outcomes of the earthquake scenario described in the text. Shown are results from the three different GMPEs. Rows a, b and c show three randomly selected different scenario results that could be expected, based on sampling the uncertainty in the GMPEs at each location differently. PGA values are saturated at $2.1 \mathrm{~g}$.

\subsection{Scenario Hazard Results}

Scenario results show that a large proportion of Bhutan could experience very significant shaking (Fig. 9) and intensity levels (Fig. S2 in Online Resource 1). Hazard is concentrated above the fault rupture zone but also extends further afield. Shaking is slightly concentrated in the south on the Brahmaputra Plain, due to the fault plane being very shallow and VS30 being low there. This is of particular concern as this is an area of high population density.

Because of uncertainties and natural variability in shaking from earthquakes of similar size and location, there are many different outcomes for the same size and location of earthquake. The variability is shown between different GMPEs (one for each column) and for different sampling of the uncertainties in the GMPEs at each point, shown in possibilities a, b, and c. From different scenarios for the same event, certain locations could vary between 
having low-moderate shaking $(\sim 0.4 \mathrm{~g})$ and very high shaking of more than $2 \mathrm{~g}$ because of this uncertainty in the GMPEs, as shown for three population centres in Fig. 10. In Section 4 we study PSHA results, where thousands of earthquakes are simulated, which all sample the uncertainties differently, leading to an average outcome, which is easier to predict than the results from one specific event.

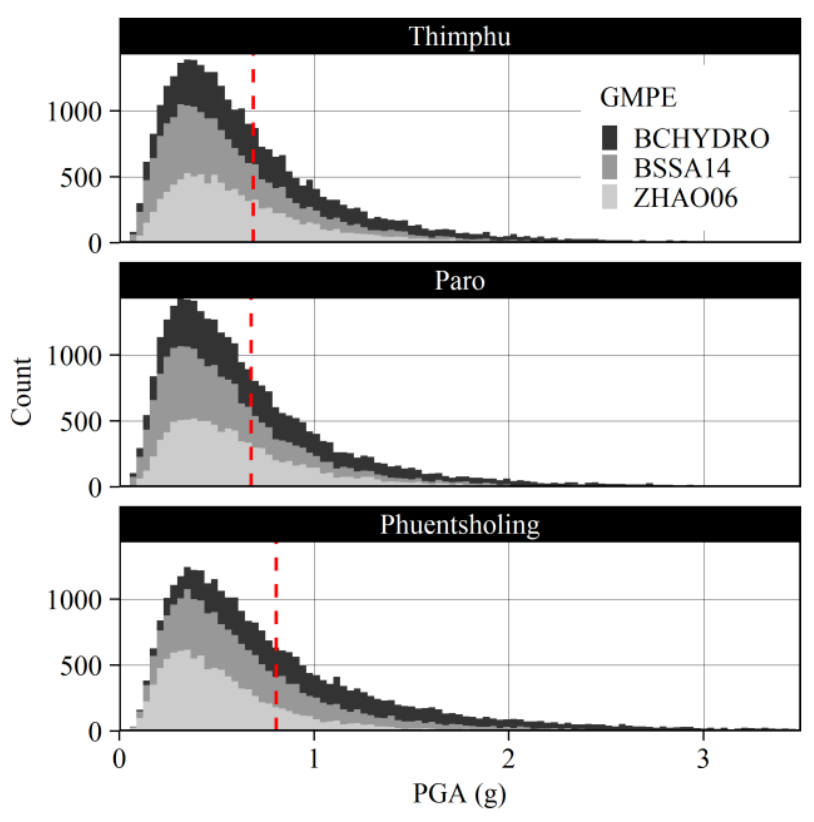

491

492

493

494

495

496

497

498

499

500

501

502

503

504

505

506

507

Fig. 10 Scenario hazard results for three population centres. PGA (g) values for 10,000 potential outcomes of the earthquake scenario described in the text at Thimphu, Paro and Phuentsholing, shaded by GMPE. The vertical dashed line shows the mean PGA (g). For population centre locations, see Fig. 16.

\subsection{Scenario Risk Results}

The $1714 \mathrm{M}_{\mathrm{w}} 8$ earthquake can be used to study the sensitivity of the risk analysis framework to the different exposure and vulnerability components. To retrospectively analyse this event, a typical scenario-based approach is adopted. The hazard is simulated using the ground motion prediction equation proposed by Allen, Wald and Worden (2012) (see Fig. S2 in Online Resource 1). A total of 10,000 shakemaps are simulated to take into account the uncertainties in the hazard prediction.

Figs. 11 and 12 show the loss curves obtained for the three main cities of the country obtained with the four different models presented above. Models M1 and M2 provide a more conservative estimation of the losses with respect to the other two models. Fig. 11(d) and Fig. 12(d) show the loss curves for the three considered cities in terms of collapsed buildings and affected people. It is possible to observe that for very severe cases (i.e. low probability of occurrence) the entire population of the cities may result affected. 

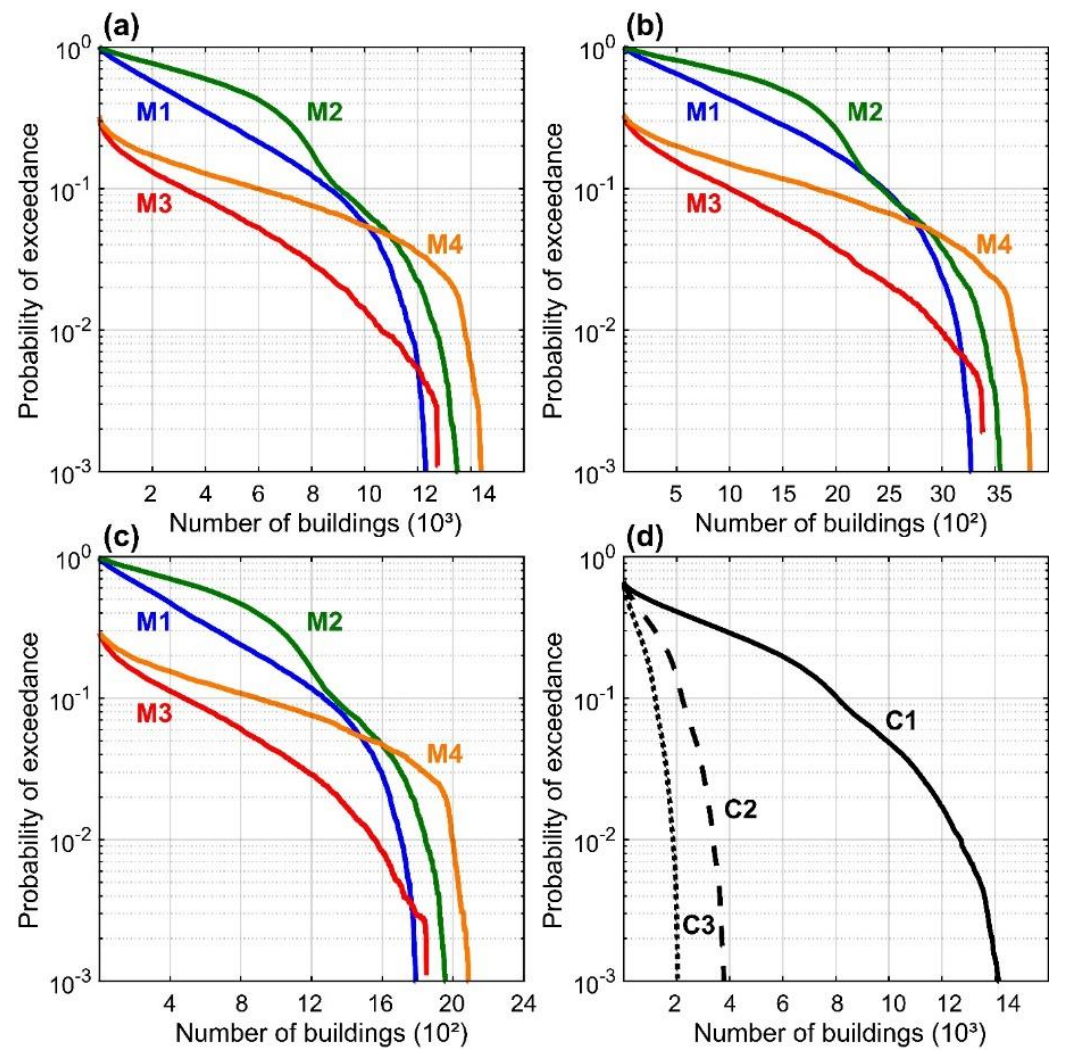

Fig. 11 Loss curves in terms of number of damaged buildings for (a) Thimphu, (b) Phuentsholing, and (c) Paro.

(d) Mean loss curves for (C1) Thimphu, (C2) Phuentsholing, and (C3) Paro.
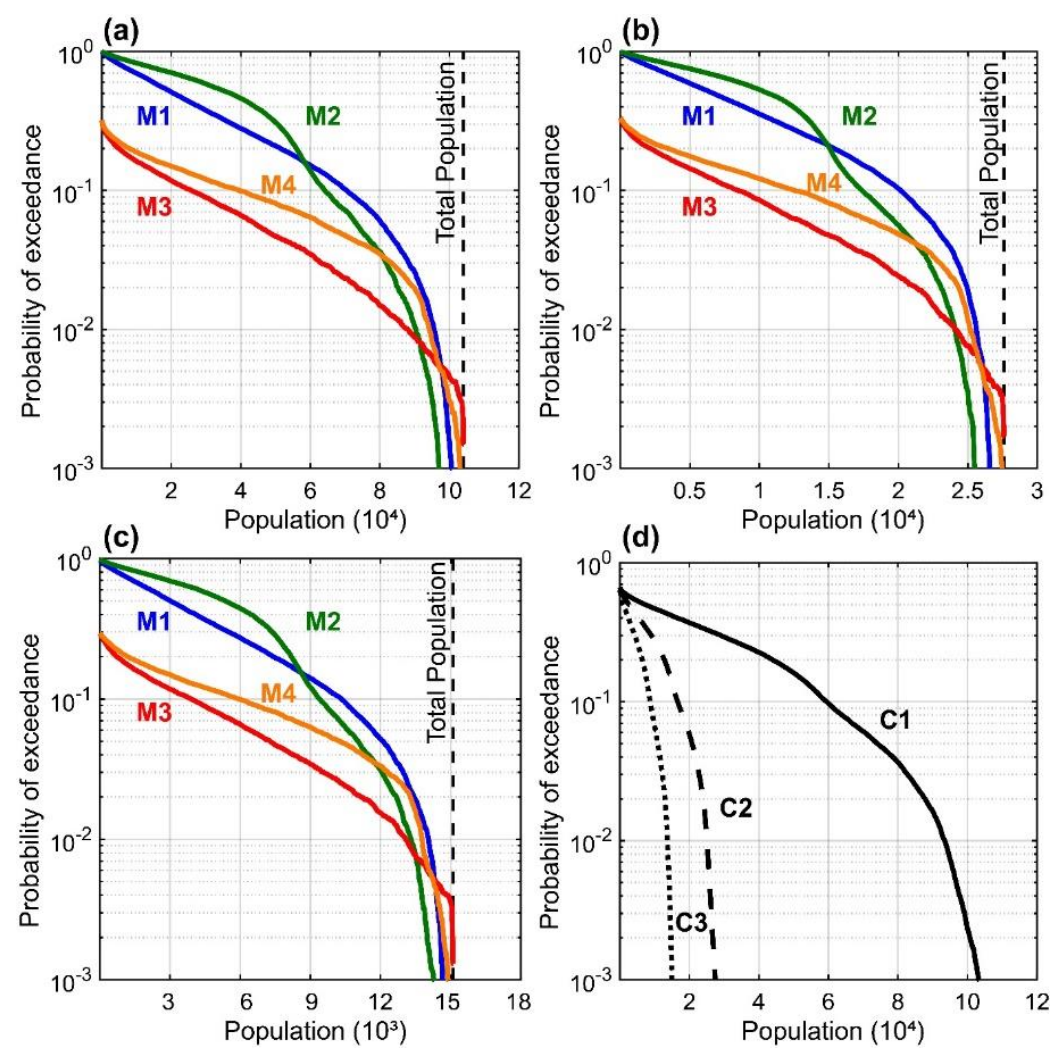

Fig. 12 Loss curves in terms of people affected for (a) Thimphu, (b) Phuentsholing, and (c) Paro. (d) Mean loss curves for (C1) Thimphu, (C2) Phuentsholing, and (C3) Paro. 

to identify hotspots and prioritise mitigation interventions, if possible. The maps reflect population density in general (Fig. 4), with further emphasis on steeply incised valleys and the topographic front of the Himalaya.
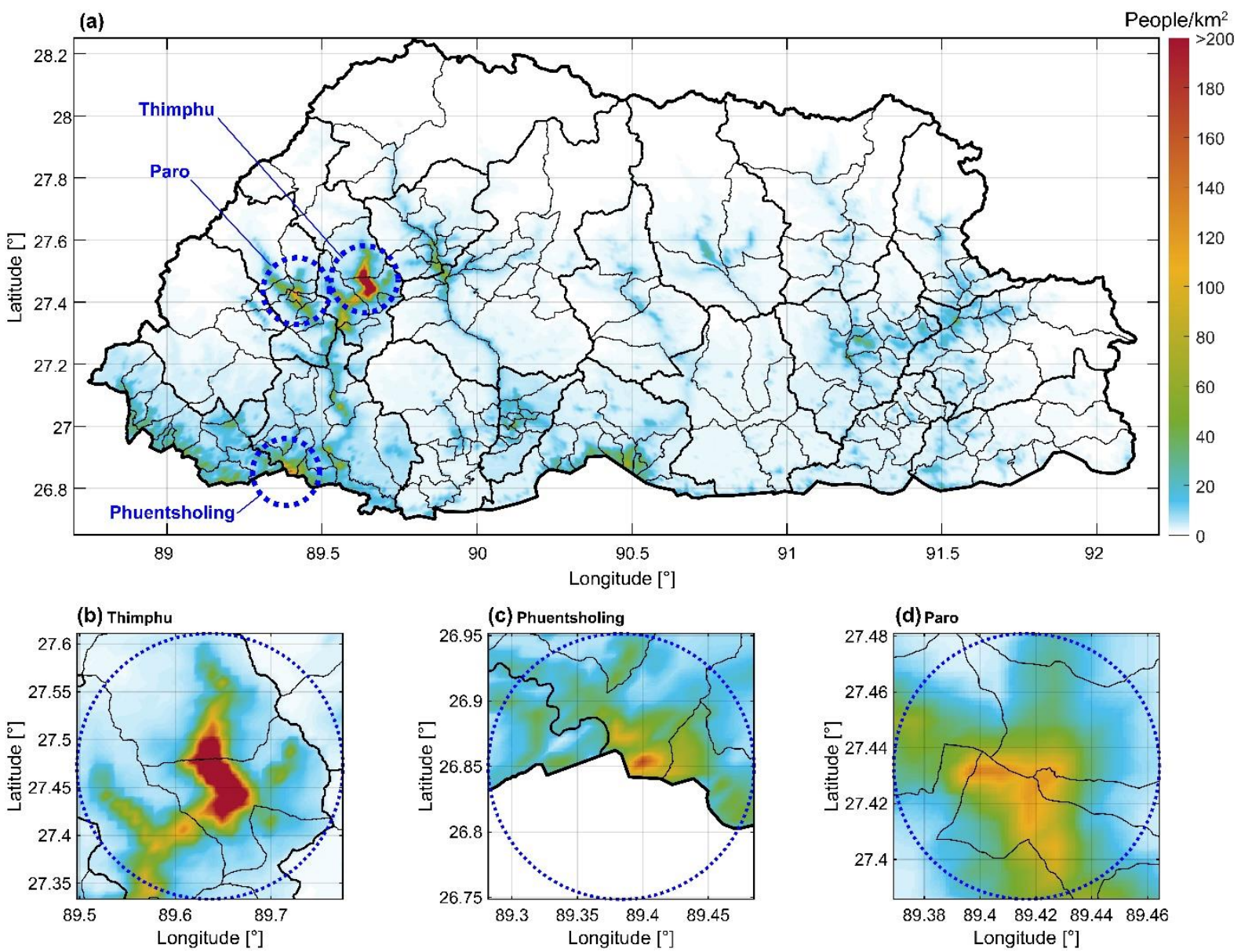

Fig. 13 Mean loss in terms of number of affected people.

\section{Probabilistic Seismic Hazard and Risk}

\subsection{PSHA-based Hazard}

Fig. 14 shows the hazard results in PGA (results for MMI are shown in Fig. S3 in Online Resource 1). The MHT is the greatest source of hazard, with PGA values of 0.7-1.1 g and 1.2-2.1 g above the fault for a 10 and $2 \%$ chance in 50 years respectively. The depth of the fault beneath Bhutan, and the northern seismogenic extent of the fault (here controlled by the coupling) along with the VS30 values, are the main controls on the hazard coming from this fault. The gentle northward dip of the fault means that the fault depth increases gradually to the north, so the distance from the fault plane increases and the hazard decreases. Earthquakes can occur on the fault up to the northern seismogenic extent, so further north than this edge, the distance from the fault plane again increases, and the hazard quickly decreases. The VS30 values (see Fig. 2) change rapidly from the sediments of the Brahmaputra Plain at the very southern edge of Bhutan $(200-300 \mathrm{~m} / \mathrm{s})$, to the much thinner sediments covering much of Bhutan's valleys (700-800 m/s). The lower VS30 values lead to an amplification of PGA, and since the MHT reaches the surface there, the highest hazard values are there. The strike-slip faults cutting across the 
532 Himalaayas at depth and the extensional grabens to the north of Bhutan are a secondary, localized hazard. This

533 non-uniform hazard across Bhutan could be used to update the building code, which currently uses a uniform

534 PGA of $0.36 \mathrm{~g}$ across the country, a value almost half that of what we find would be reached with a $10 \%$ chance 535 in 50 years.

536 The capital, Thimphu, (at roughly $89.65^{\circ} \mathrm{E}, 27.5^{\circ} \mathrm{N}$ ) contains the most significant concentration of population with

$537 \sim 100,000$ inhabitants. It lies above the MHT, towards its northern extent and is built within a valley, which since

538 it is flat, has lower VS30 values, which increases the hazard results within the valley itself, as shown in Fig. 15.

539 We further analyse the seismic hazard at twelve population centres, as shown in Fig. 16, which shows the 540 probability of exceeding different acceleration levels in a period of 50 years. The population centres furthest north 541 generally have a lower hazard relative to other regions, with some influence from VS30 levels at their locations, 542 and the three most southerly population centres have the highest hazard.

543 


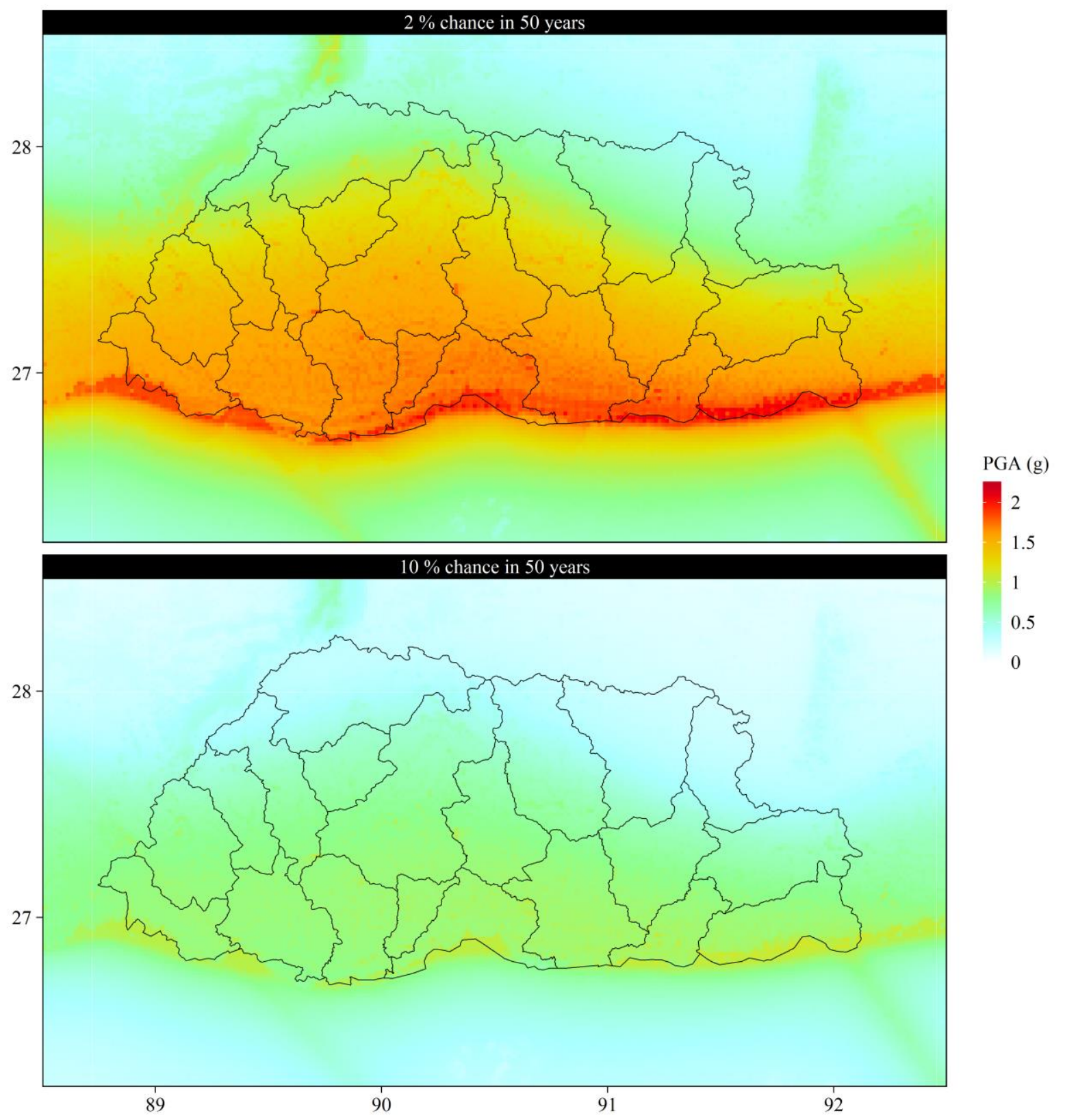

Fig. 14 Hazard results for Bhutan. PGA (g) with a 2 and $10 \%$ chance of exceedance in 50 years. Districts (Dzongkhags) of Bhutan are shown. 


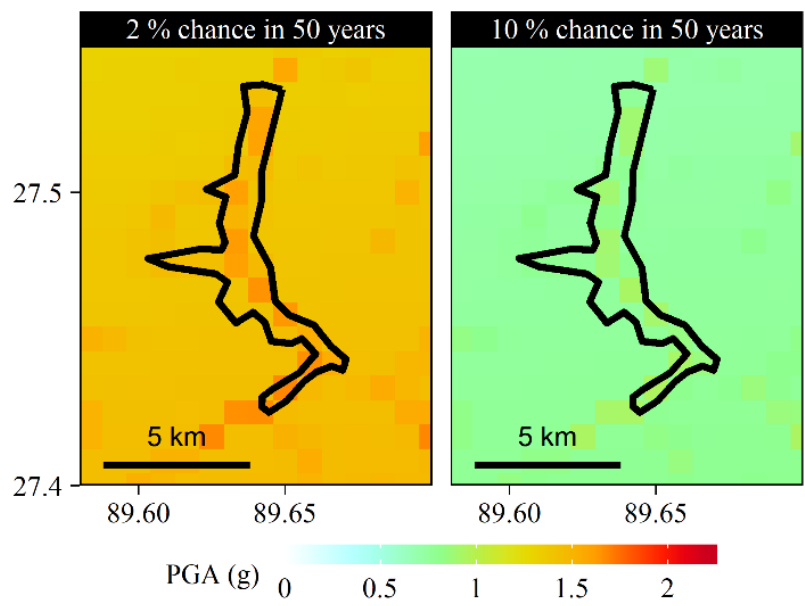

Fig. 15 Hazard results for Thimphu. PGA (g) with a 2 and $10 \%$ chance of exceedance in 50 years. The solid line shows the outline of the capital, Thimphu City.

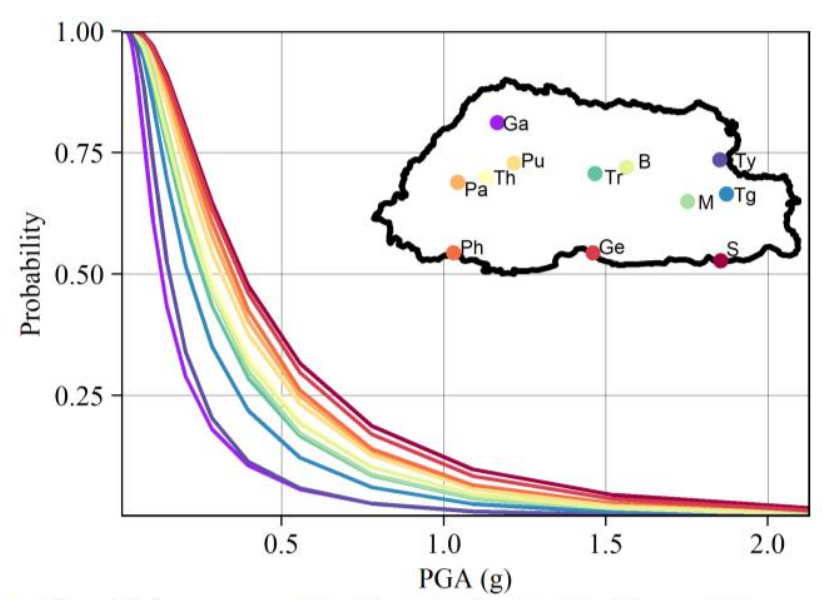

$$
\begin{array}{lll}
\text { - Gasa }(\mathrm{Ga}) & - \text { Trashiyangtse }(\mathrm{Ty}) & - \text { Trashigang }(\mathrm{Tg}) \\
- \text { Trongsa }(\mathrm{Tr}) & - \text { Mongar }(\mathrm{M}) & - \text { Bumthang }(\text { Jakar })(\mathrm{B}) \\
\text { Thimphu }(\mathrm{Th}) & - \text { Punakha }(\mathrm{Pu}) & - \text { Paro }(\mathrm{Pa}) \\
- \text { Phuentsholing }(\mathrm{Ph}) & - \text { Gelephu }(\mathrm{Ge}) & - \text { Samdrup Jongkhar }(\mathrm{S})
\end{array}
$$

Fig. 16 Hazard curves showing the probability of exceeding different acceleration levels in 50 years for twelve different population centres in Bhutan.

\subsection{PSHA-based Risk}

Fig. 17 shows the expected annual loss in terms of affected people per $\mathrm{km}^{2}$. A total expected annual loss of 768 buildings and 5693 affected people is calculated for the entirety of Bhutan. If we assume buildings value on average $\$ 45,000$ (Ministry of Works and Human Settlement, Bhutan), this could lead to a monetary loss per year of $\$ 34,560,000$. For the three main cities investigated in this study, a significant annual impact is expected: 93 buildings and 689 people for Thimphu; 29 buildings and 217 people for Phuentsholing; and, finally, 14 buildings and 102 people for Paro. These represent 6.6-7.9 \% of the population every year. 

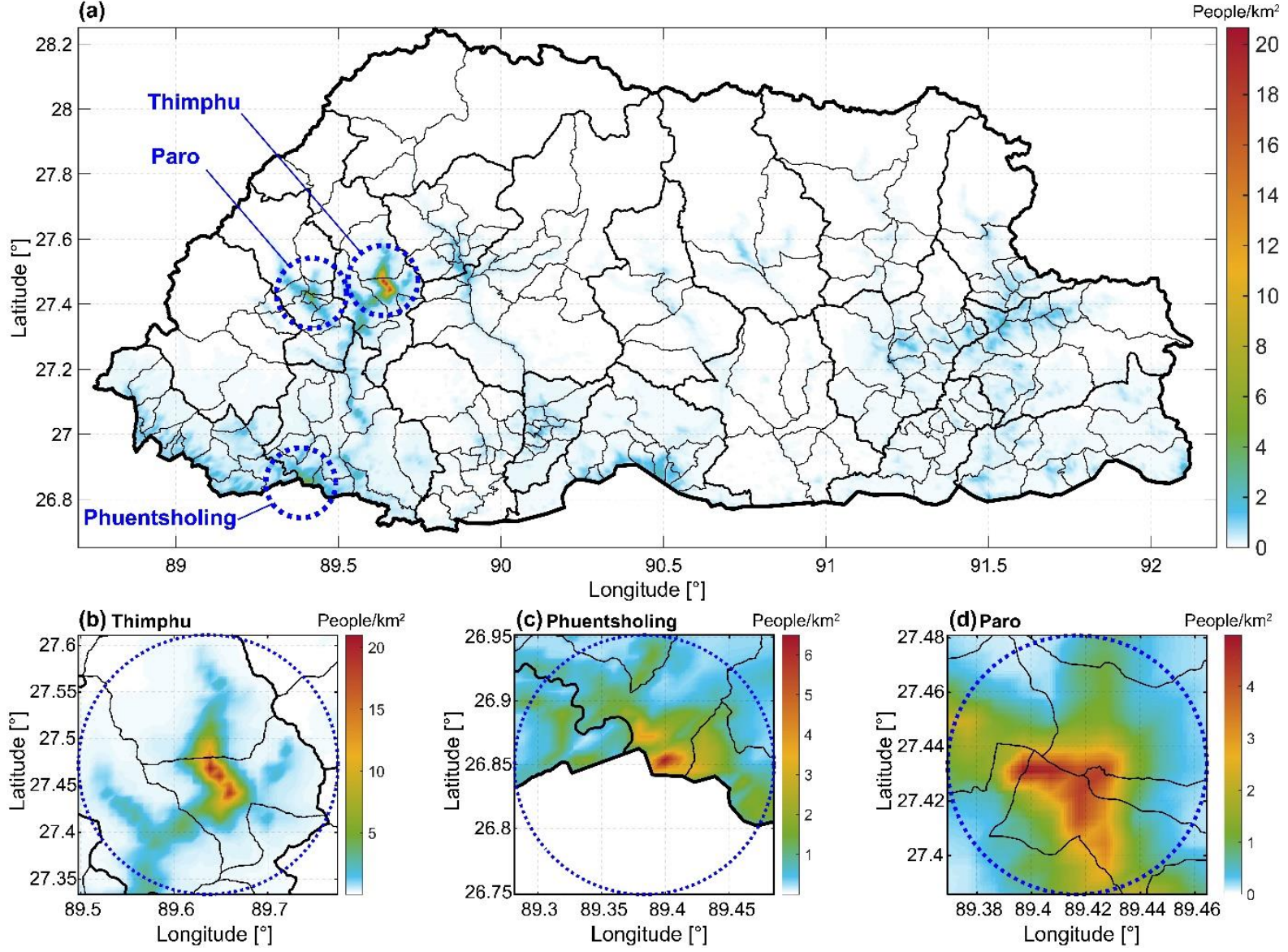

Fig. 17 Expected annual loss in terms of affected people per $\mathrm{km}^{2}$. Note the different colour scales.

\section{Discussion}

567 The choice of GMPE for the MHT has a large influence on the results (see Fig. 9, 10 and Fig. S4 in Online Resource 1). In general, the use of BCHYDRO leads to the highest hazard, followed by BSSA14 and ZHAO06 gives the lowest hazard. In the ZHAO06 model, the hazard decreases faster than the other models from the south to the north of Bhutan because it is more dependent on the epicentral depth of the earthquake than the other models, and the MHT is shallowest in the south.

572 We do not consider secondary earthquake hazards here such as landslides and liquefaction, however these can be very damaging and delay vital emergency response by blocking roads. In Bhutan, the southernmost area of the country has a higher risk of liquefaction, since there are water-saturated sediments here, with liquefaction seen extensively in the Ganges Plains regions near Nepal after the 1934 earthquake (Rana, 1935; Pandey and Molnar, 1988) and also near the Shillong Plateau after the 1897 earthquake (Oldham, 1899). Landslides after the more recent 2015 Gorkha Nepal earthquake directly caused fatalities, and also cut off remote regions of the country e.g. the Langtang Valley (Jones et al., 2019). Although forest coverage of $>60 \%$ is prescribed by the Bhutanese constitution, and most of the outcropping rocks are harder rocks of the Greater Himalayan Series, there are areas of weaker geology where landslides are a serious risk (Dikshit et al., 2020). In Bhutan this is highly critical as the 
road network resembles a fishbone with very few, to no alternative routes from the main east-west highway, and helicopter landing spots are scarce.

In this study we have considered the average hazard expected in any 50-year time period, without taking into account any recent changes in stress state or probability of future earthquakes based on historical earthquakes in the region. If the $1714 \mathrm{M}_{\mathrm{w}} 8$ earthquake did not rupture the very eastern side of Bhutan, it could mean that this area may now have a higher probability of a large future earthquake than the rest of Bhutan, though this also depends on the extent of older past large ruptures, which is not known very well. Recent trenching suggests that at least one large earthquake has ruptured eastern Bhutan in the past 1000 years (Zhao et al., 2019), though the exact date is not yet well known. The return time of $550 \pm 210$ years for major earthquakes (Le Roux-Mallouf et al., 2020) leaves room for various scenarios.

591 Outside the seismogenic section of the MHT, proximity to the other fault sources is the main influence on the distribution of seismic hazard. Therefore, the location of these sources becomes important. For the northern extensional grabens, the graben can be seen in the topography, however for the crosscutting strike-slip faults at depth, there is no evidence of surface rupture, and while the microseismicity gives a general indication of where these faults may be in the deeper crust, the exact geometry and seismogenic area of the faults here are not precisely known. The locational uncertainty here only has importance for hazard locally.

For risk, the estimates have significant variability depending on the adopted seismic vulnerability models. We cannot say which of the plausible vulnerability models is the most suitable. Therefore, a composite vulnerability model has been used, rather than a single one. In other words, the vulnerability models affect the building-collapse risk curves significantly. It is therefore imperative to carry out sensitivity analysis related to the choice and weighting of the seismic vulnerability models to gain further insights on derived risk predictions. At the same time, both exposure and vulnerability assessments in the field are essential to obtain a proper evaluation of the seismic risk and to propose seismic risk mitigation actions. This is especially important for recently or currently built hydropower infrastructures in most cross-Himalayan valleys in Bhutan, which is beyond the scope of this work.

\section{Conclusion}

In this paper, we have shown the results of a probabilistic seismic hazard and risk analyses for Bhutan. They show that Bhutan has a significant level of seismic hazard and subsequent risk, which are here quantified and should be considered to update building codes. There are still many areas for future work in the region to help improve the model, including refining the probable frequency of larger events on the MHT in this region, developing regional GMPEs, and proper characterisation of the exposure and vulnerability models specific to typical Bhutanese structural typologies. Developing regional GMPEs would require more broadband seismometers in the region, and may take time for enough data to be collected before they could be created. As an input to GMPEs, the proxy VS30 measurements used here could be ground-truthed using geophysical/borehole methods. This is especially important for Thimphu and Paro which sit on large filled sediment valleys. A further step might be to consider time-dependent hazard based on the size and rupture extent of past earthquakes. All these steps can be undertaken in the frame of future science and development projects in Bhutan. 
Abrahamson, N., Gregor, N. and Addo, K. (2016) 'BC Hydro Ground Motion Prediction Equations for 623 Subduction Earthquakes', Earthquake Spectra, 32(1), pp. 23-44. doi: 10.1193/051712EQS188MR.

Allen, T. I., Wald, D. J. and Worden, C. B. (2012) 'Intensity attenuation for active crustal regions', Journal of Seismology, 16(3), pp. 409-433. doi: 10.1007/s10950-012-9278-7.

Asimaki, D. et al. (2017) 'Observations and Simulations of Basin Effects in the Kathmandu Valley During the 2015 Gorkha, Nepal, Earthquake Sequence', Earthquake Spectra, 33(S1), pp. S35-S53. doi:

628 10.1193/013117EQS022M.

Barman, P. et al. (2016) 'Estimation of present-day inter-seismic deformation in Kopili fault zone of north-east India using GPS measurements', Geomatics, Natural Hazards and Risk, 7(2), pp. 586-599. doi: 10.1080/19475705.2014.983187.

Berthet, T. et al. (2014) 'Active tectonics of the eastern Himalaya: New constraints from the first tectonic geomorphology study in southern Bhutan', Geology. GeoScienceWorld, 42(5), pp. 427-430. doi: 10.1130/G35162.1.

Bhatia, S. C., Kumar, M. R. and Gupta, H. K. (1999) 'A probabilistic seismic hazard map of India and adjoining regions', Annali di Geofisica, 42(6), pp. 1153-1164. doi: 10.4401/ag-3777.

Bilham, R. and England, P. (2001) 'Plateau "pop-up” in the great 1897 Assam earthquake', Nature. Nature Publishing Group, 410(6830), pp. 806-809. doi: 10.1038/35071057.

BIS-1893 (2002) Indian Standard Criteria for Earthquake Resistant Design of Structures, Part 1 - General

640 Provisions and Buildings. New Delhi.

Bollinger, L. et al. (2014) 'Estimating the return times of great Himalayan earthquakes in eastern Nepal: Evidence from the Patu and Bardibas strands of the Main Frontal Thrust', Journal of Geophysical Research: Solid Earth. John Wiley \& Sons, Ltd, 119(9), pp. 7123-7163. doi: 10.1002/2014JB010970.

Boore, D. M. et al. (2014) 'NGA-West2 Equations for Predicting PGA, PGV, and 5\% Damped PSA for Shallow Crustal Earthquakes', Earthquake Spectra. Earthquake Engineering Research Institute , 30(3), pp. 1057-1085. doi: 10.1193/070113EQS184M.

Chen, W.-P. and Molnar, P. (1977) 'Seismic moments of major earthquakes and the average rate of slip in central Asia', Journal of Geophysical Research, 82(20), pp. 2945-2969. doi: 10.1029/JB082i020p02945.

Chiou, B. S.-J. and Youngs, R. R. (2014) 'Update of the Chiou and Youngs NGA Model for the Average 1153. doi: 10.1193/072813EQS219M.

CIESIN (2016) Center for International Earth Science Information Network - CIESIN - Columbia University. Socioeconomic Data and Applications Center (SEDAC). doi: 10.1017/CBO9781107415324.004.

Coudurier-Curveur, A. et al. (2020) 'A composite rupture model for the great 1950 Assam earthquake across the cusp of the East Himalayan Syntaxis', Earth and Planetary Science Letters. Elsevier B.V., 531, p. 115928. doi: 10.1016/j.epsl.2019.115928.

Coutand, I. et al. (2014) 'Geometry and kinematics of the Main Himalayan Thrust and Neogene crustal exhumation in the Bhutanese Himalaya derived from inversion of multithermochronologic data', Journal of Geophysical Research: Solid Earth. John Wiley \& Sons, Ltd, 119(2), pp. 1446-1481. doi:

662 Cua, G. et al. (2010) Best Practices for using macroseismic intensity and ground motion intensity conversion 663 equations for Hazard and Loss Models in GEM1. Pavia.

664 De, R. and Kayal, J. R. (2003) 'Seismotectonic Model of the Sikkim Himalaya: Constraint from 665 Microearthquake Surveys', Bulletin of the Seismological Society of America. GeoScienceWorld, 93(3), pp. 
667 Diehl, T. et al. (2017) 'Seismotectonics of Bhutan: Evidence for segmentation of the Eastern Himalayas and link to foreland deformation', Earth and Planetary Science Letters. Elsevier, 471, pp. 54-64. doi: 10.1016/j.epsl.2017.04.038.

670 Dikshit, A. et al. (2020) 'Spatial landslide risk assessment at Phuentsholing, Bhutan', Geosciences. MDPI AG, 671 10(4), p. 131. doi: 10.3390/geosciences 10040131.

672 Dobson, J. E. et al. (2000) 'LandScan: A global population database for estimating populations at risk', in 673 Photogrammetric Engineering and Remote Sensing. London: Taylor \& Francis, pp. 849-857.

674 Drukpa, D., Velasco, A. A. and Doser, D. I. (2006) 'Seismicity in the Kingdom of Bhutan (1937-2003): 675 Evidence for crustal transcurrent deformation', Journal of Geophysical Research: Solid Earth, 111(B6). doi: $67610.1029 / 2004 J B 003087$.

677 Dziewonski, A. M., Chou, T.-A. A. and Woodhouse, J. H. (1981) 'Determination of earthquake source 678 parameters from waveform data for studies of global and regional seismicity.', Journal of Geophysical 679 Research. John Wiley \& Sons, Ltd, 86(B4), pp. 2825-2852. doi: 10.1029/JB086iB04p02825.

680 Ekström, G. et al. (2012) 'The global CMT project 2004-2010: Centroid-moment tensors for 13,017 681 earthquakes', Physics of the Earth and Planetary Interiors. Elsevier, 200-201, pp. 1-9. doi: 682 http://dx.doi.org/10.1016/j.pepi.2012.04.002.

683 England, P. and Bilham, R. (2015) 'The Shillong Plateau and the great 1897 Assam earthquake', Tectonics. 684 John Wiley \& Sons, Ltd, 34(9), pp. 1792-1812. doi: 10.1002/2015TC003902.

Field, E. H. et al. (2014) 'Uniform California Earthquake Rupture Forecast, Version 3 (UCERF3) - The TimeIndependent Model', Bulletin of the Seismological Society of America, 104(3), pp. 1122-1180. doi: $10.1785 / 0120130164$.

688 Foulser-Piggott, R., Bowman, G. and Hughes, M. (2020) 'A Framework for Understanding Uncertainty in Seismic Risk Assessment’, Risk Analysis. Blackwell Publishing Inc., 40(1), pp. 169-182. doi: 10.1111/risa.12919.

Gan, W. et al. (2007) 'Present-day crustal motion within the Tibetan Plateau inferred from GPS measurements', J. Geophys. Res. AGU, 112(B8), pp. B08416--. Available at: http://dx.doi.org/10.1029/2005JB004120.

Gee, E. R. (1934) 'The Dhubri Earthquake of the 3rd July, 1930', Memory of Geological Survey of India, 65, pp. $1-106$.

Goda, K. et al. (2016) 'Seismic risk assessment of urban and rural settlements around lake malawi', Frontiers in Built Environment. Frontiers Media S.A., 2, p. 30. doi: 10.3389/fbuil.2016.00030.

Grujic, D. et al. (2018) 'Stress transfer and connectivity between the Bhutan Himalaya and the Shillong

Plateau', Tectonophysics. Elsevier, 744, pp. 322-332. doi: 10.1016/j.tecto.2018.07.018.

Grünthal, G. (1998) European Macroseismic Scale 1998 (EMS - 98), Cahiers du Centre Européen de

701 http://scholar.google.com/scholar?hl=en\&btnG=Search\&q=intitle:European+Macroseismic+Scale+1998\#0

702 (Accessed: 5 April 2020).

Gutenberg, B. and Richter, C. F. (1944) 'Frequency of earthquakes in California', Bulletin of the Seismological

Hauck, M. L. et al. (1998) 'Crustal structure of the Himalayan orogen at $-90^{\circ}$ east longitude from Project INDEPTH deep reflection profiles', Tectonics. John Wiley \& Sons, Ltd, 17(4), pp. 481-500. doi: $10.1029 / 98 \mathrm{TC} 01314$.

Hetényi, G., Le Roux-Mallouf, R., et al. (2016) 'Joint approach combining damage and paleoseismology 43(20), pp. 10,695-10,702. doi: 10.1002/2016GL071033. 
Jaiswal, K., Wald, D. and D'Ayala, D. (2011) 'Developing empirical collapse fragility functions for global building types’, Earthquake Spectra, 27(3), pp. 775-795. doi: 10.1193/1.3606398.

Jaiswal, K. and Wald, D. J. (2008) 'Creating a Global Building Inventory for Earthquake Loss Assessment and Risk Management’, US. doi: 10.3133/OFR20081160.

Jones, J. N. et al. (2019) 'Coseismic and monsoon-triggered landslide impacts on remote trekking infrastructure,

718 Langtang Valley, Nepal', Quarterly Journal of Engineering Geology and Hydrogeology. Geological Society of 719 London, pp. qjegh2019-048. doi: 10.1144/qjegh2019-048.

Kayal, J. R. et al. (2006) 'Shillong plateau earthquakes in northeast India region: complex tectonic model', Current Science. Current Science Association, pp. 109-114. doi: 10.2307/24094186.

Lang, D. H., Singh, Y. and Namgyel, K. (2013) Building Classification Scheme for Bhutan, EQRisk project report. Thimphu.

Marechal, A. et al. (2016) 'Evidence of interseismic coupling variations along the Bhutan Himalayan arc from new GPS data', Geophysical Research Letters, 43(24), pp. 12,399-12,406. doi: 10.1002/2016GL071163.

Miano, A. et al. (2016) 'Model updating and seismic loss assessment for a portfolio of bridges', Bulletin of

Earthquake Engineering. Springer Netherlands, 14(3), pp. 699-719. doi: 10.1007/s10518-015-9850-y.

Morino, M. et al. (2014) 'A paleo-seismological study of the Dauki fault at Jaflong, Sylhet, Bangladesh: Historical seismic events and an attempted rupture segmentation model', Journal of Asian Earth Sciences. Elsevier Ltd, 91, pp. 218-226. doi: 10.1016/j.jseaes.2014.06.002.

Oldham, R. D. (1899) 'Report on the great earthquake of 12th June, 1897', Memory of Geological Survey of India. Calcutta: Office of the Geological Survey, 29, pp. 1-379. Available at:

https://www.worldcat.org/title/report-of-the-great-earthquake-of-12th-june-1897/oclc/2201380 (Accessed: 26 September 2019).

Pandey, M. R. and Molnar, P. (1988) 'The distribution of intensity of the Bihar-Nepal earthquake of 15 January 1934 and bounds on the extent of the rupture zone', Journal of Nepal Geological Society. Nepal Geological Society, 5(1), pp. 22-44.

Paul, H. et al. (2015) 'Active transverse faulting within underthrust Indian crust beneath the Sikkim Himalaya', Geophysical Journal International. Narnia, 201(2), pp. 1072-1083. doi: 10.1093/gji/ggv058.

Polidoro, B. and Spence, R. (2015) 'The development of new buildings vulnerability relationships using the CEQID database', in SECED 2015 Conference. Cambridge, pp. 1-10.

Rana, B. S. (1935) Nepal Ko Maha Bhukampa (The great earthquake of Nepal). Kathmandu: Jorganesh Press.

De Risi, R. et al. (2013) 'Flood risk assessment for informal settlements', Natural Hazards. Springer, 69(1), pp. 1003-1032. doi: 10.1007/s11069-013-0749-0.

De Risi, R. et al. (2018) 'Life Cycle Cost and Return on Investment as complementary decision variables for urban flood risk management in developing countries', International Journal of Disaster Risk Reduction. Elsevier Ltd, 28, pp. 88-106. doi: 10.1016/j.ijdrr.2018.02.026.

De Risi, R., Penna, A. and Simonelli, A. L. (2019) 'Seismic risk at urban scale: the role of site response analysis', Soil Dynamics and Earthquake Engineering. Elsevier Ltd, 123, pp. 320-336. doi: 10.1016/j.soildyn.2019.04.011.

Robinson, T. R. (2020) 'Scenario ensemble modelling of possible future earthquake impacts in Bhutan', Natural

Le Roux-Mallouf, R. et al. (2015) 'Evidence for a wide and gently dipping Main Himalayan Thrust in western Bhutan', Geophysical Research Letters. John Wiley \& Sons, Ltd, 42(9), pp. 3257-3265. doi: 10.1002/2015GL063767. 
Le Roux-Mallouf et al. (2020) 'A 2600-yr-long paleoseismic record for the Himalayan Main Frontal Thrust (Western Bhutan).', Manuscript submitted for publication.

763 Scholz, C. H. (2002) The Mechanics of Earthquakes and Faulting. Cambridge University Press. doi: $764 \quad 10.1017 / 9781316681473$.

765

Scordilis, E. M. (2006) 'Empirical Global Relations Converting M S and m b to Moment Magnitude', Journal of Seismology. Springer Netherlands, 10(2), pp. 225-236. doi: 10.1007/s10950-006-9012-4.

Singer, J. et al. (2017) 'The underthrusting Indian crust and its role in collision dynamics of the Eastern Himalaya in Bhutan: Insights from receiver function imaging', Journal of Geophysical Research: Solid Earth. John Wiley \& Sons, Ltd, 122(2), pp. 1152-1178. doi: 10.1002/2016JB013337.

So, E. and Spence, R. (2013) 'Estimating shaking-induced casualties and building damage for global earthquake events: A proposed modelling approach', Bulletin of Earthquake Engineering. Springer, 11(1), pp. 347-363. doi: $10.1007 / \mathrm{s} 10518-012-9373-8$.

Stevens, F. R. et al. (2015) 'Disaggregating census data for population mapping using Random forests with remotely-sensed and ancillary data', PLOS ONE. Edited by L. A. N. Amaral. Public Library of Science, 10(2), p. e0107042. doi: 10.1371/journal.pone.0107042.

Stevens, V. L. L. and Avouac, J. P. P. (2015) 'Interseismic coupling on the main Himalayan thrust', Geophysical Research Letters, 42(14), pp. 5828-5837. doi: 10.1002/2015GL064845.

Stevens, V. L., Shrestha, S. N. and Maharjan, D. K. (2018) 'Probabilistic seismic hazard assessment of Nepal', Bulletin of the Seismological Society of America, 108(6), pp. 3488-3510. doi: 10.1785/0120180022.

Styron, R., Taylor, M. and Okoronkwo, K. (2010) 'Database of Active Structures From the Indo-Asian Collision', Eos, Transactions American Geophysical Union, 91(20), pp. 181-182. doi: 10.1029/2010EO200001.

Tatem, A. J. (2017) 'WorldPop, open data for spatial demography', Scientific Data. Nature Publishing Groups, pp. 1-4. doi: 10.1038/sdata.2017.4.

Velasco, A. A. et al. (2007) 'Using small, temporary seismic networks for investigating tectonic deformation: Brittle deformation and evidence for strike-slip faulting in Bhutan', Seismological Research Letters. GeoScienceWorld, 78(4), pp. 446-453. doi: 10.1785/gssrl.78.4.446.

Vernant, P. et al. (2014) 'Clockwise rotation of the Brahmaputra Valley relative to India: Tectonic convergence in the eastern Himalaya, Naga Hills, and Shillong Plateau', Journal of Geophysical Research: Solid Earth. John Wiley \& Sons, Ltd, 119(8), pp. 6558-6571. doi: 10.1002/2014JB011196.

Wald, D. J. and Allen, T. I. (2007) 'Topographic Slope as a Proxy for Seismic Site Conditions and Amplification', Bulletin of the Seismological Society of America, 97(5), pp. 1379-1395. doi: 10.1785/0120060267.

Wang, Y. et al. (2019) 'Differential crustal deformation across the Cona-Oiga rift, southern Tibetan Plateau', Journal of Asian Earth Sciences, 177, pp. 177-185. doi: https://doi.org/10.1016/j.jseaes.2019.03.023.

Wells, D. L. and Coppersmith, K. J. (1994) 'New empirical relationships among magnitude, rupture length, rupture width, rupture area, and surface displacement', Bulletin of the Seismological Society of America, 84(4), pp. 974-1002,A1-A4,B1-B11,C1-C49. Available at: http://www.bssaonline.org/content/84/4/974.abstract.

Wu, C. et al. (1998) 'Yadong cross structure and South Tibetan Detachment in the east central Himalaya $\left(89^{\circ}-\right.$ 90 E)', Tectonics, 17(1), pp. 28-45. doi: 10.1029/97TC03386.

Wu, Z. H. et al. (2008) 'The quaternary normal faulting of the Cona-Oiga rift', Dizhen Dizhi, 30(1), pp. 144160.

Yin, A. (2006) 'Cenozoic tectonic evolution of the Himalayan orogen as constrained by along-strike variation of structural geometry, exhumation history, and foreland sedimentation', Earth-Science Reviews, 76(1), pp. 1-131. doi: https://doi.org/10.1016/j.earscirev.2005.05.004.

Zhao, J. X. et al. (2006) 'Attenuation Relations of Strong Ground Motion in Japan Using Site Classification Based on Predominant Period', Bulletin of the Seismological Society of America. Bulletin of the Seismological 
807 Society of America, 96(3), pp. 898-913. doi: 10.1785/0120050122.

808 Zhao, Y. et al. (2019) 'Recurrence Interval of Large Earthquakes in the Eastern Himalaya', in Abstract volume

809 of the 34th Himalaya-Karakorum-Tibet Workshop, p. 87.

\section{$814 \quad$ Funding}

815 VLS was supported by the Claude Leon Foundation.

816 GH was supported by the Swiss National Science Foundation (projects PP00P2_157627 and PP00P2_187199).

817 RDR was supported by EPSRS project PREPARE (EP/P028233/1).

\section{Conflicts of interest/Competing interests}

819 The authors declare that they have no conflict of interest.

820 Availability of data and material

821 PGA (g) at 2 and $10 \%$ chance in 50 years can be found in Online Resource 2

822 Code availability

823 Not applicable

824 Online Resources (Captions)

825 Online Resource 1: Supplementary Figures

826 Online Resource 2: PGA (g) at 2 and $10 \%$ chance in 50 years 